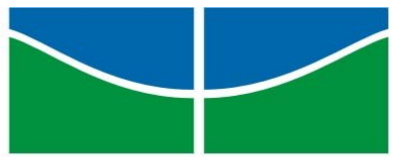

Universidade de Brasília

Faculdade UnB Planaltina

Programa de Pós-Graduação em Ciência de Materiais

GUILHERME BASTOS PINHEIRO

AVALIAÇÃO DAS METODOLOGIAS DE DETERMINAÇÃO DA DENSIDADE PARA COLOIDES MAGNÉTICOS

BRASÍLIA

2015 


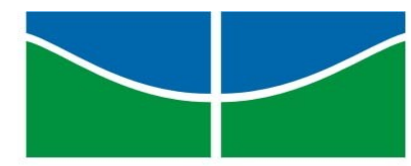

Universidade de Brasília

Faculdade UnB Planaltina

Programa de Pós-Graduação em Ciência de Materiais

\author{
GUILHERME BASTOS PINHEIRO
}

\title{
AVALIAÇÃO DAS METODOLOGIAS DE DETERMINAÇÃO DA DENSIDADE PARA COLOIDES MAGNÉTICOS
}

\begin{abstract}
Dissertação apresentada como requisito parcial para a obtenção do Título de Mestre em Ciência de Materiais pelo Programa de PósGraduação em Ciência de Materiais da Faculdade UnB Planaltina.

Área de Concentração: Ciências de Materiais Nanoestruturados Avançados

Linha de Pesquisa: Análise Química, Estrutural e Caracterização Físico-Química de Materiais
\end{abstract}

Orientador: Prof. Dr. Franciscarlos Gomes da Silva

\section{BRASÍLIA}


Pinheiro, Guilherme Bastos

Avaliação das Metodologias de Determinação da Densidade de Fluidos Magnéticos/Guilherme Bastos Pinheiro - Brasília: o autor, 2015.

49 f. Dissertação apresentada para a obtenção do título de mestre em Ciência de Materiais pelo Programa de PósGraduação em Ciência de Materiais da Universidade de Brasília/ Faculdade UnB Planaltina.

Orientador: Prof. Dr. Franciscarlos Gomes da Silva 
A minha mãe, Gecina Bastos, pelo ser humano sensível e dedicado que é, sempre presente me incentivando constantemente. 


\section{AGRADECIMENTOS}

Agradeço primeiramente ao Deus supremo, o inominável, pelo privilégio que me deu de existir nessa era, cercado de tantas pessoas queridas e espetaculares.

Aos meus pais Gecina Bastos e Wilian Sales, ao meu padrasto Francisco Oder, pelo eterno incentivo ao estudo e a busca do conhecimento. Com suor, atenção e amor, plantaram em mim a paixão pelo novo e o mistério.

Aos meus professores Franciscarlos Gomes, Renata Aquino, Alex Fabiano, Jerôme Depeyrot. Minha gratidão pela atenção, paciência e horas de trabalho, muitas vezes fora do expediente para concretização deste trabalho.

Aos meus companheiros de laboratório Elton John, Josué, Tatiana e, em especial, a Priscilla Coppola e Dyego. Desejo que Deus os recompense cada qual, segundo sua medida, pelas horas passadas, lado a lado, no árduo processo de síntese e experimentação.

A minha amiga, mulher e companheira Gabriela Meyer, aos meus amigos irmãos Américo Alves, Fernando Vieira, Ênio Alves, Ítalo Gonçalves e Ubiratan Menezes. Sou eternamente grato pela presença ao meu lado, me presenteando com risos, versos e música.

Agradeço a toda a equipe que compõem o grupo dos Fluidos Complexos - colegas, professores e funcionário -, pela atenção e bom humor ao longo deste tempo.

Um agradecimento especial à CAPES, à Universidade de Brasília e ao governo brasileiro, pelo apoio financeiro e o espaço, tão fundamentais durante todo este processo. 
"Ninguém doma um coração de poeta!"

(Augusto dos Anjos)

“Eu escrevia silêncios, noites, anotava o inexprimível. Fixava vertigens.”

(Arthur Rimbaud)

“A ave constrói o ninho; a aranha, a teia; o homem, a amizade."

(Wiliam Blake) 


\section{RESUMO}

Os fluidos magnéticos ou ferrofluidos são dispersões coloidais de nanopartículas (NP), do tipo ferrita, em um líquido portador de escolha. Nestes materiais, a forma de expressar a concentração em nanopartículas é a fração volumétrica em nanopartículas $\phi$, dada pela razão entre o volume total de partículas pelo volume da dispersão. No caso dos fluidos magnéticos estabilizados em meio aquoso ácido, as nanopartículas são do tipo núcleo/superfície e, neste trabalho, temos NP de ferrita de cobalto $\left(\mathrm{CoFe}_{2} \mathrm{O}_{4}\right)$ recobertos por

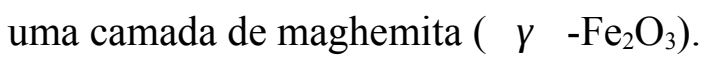

Recentemente, um modelo químico, que leva em conta a estrutura núcleo/superfície das nanopartículas, foi introduzido para determinar o $\phi$ de amostras de ferrofluidos. Nesse modelo, o cálculo da fração volumétrica é realizado a partir das concentrações molares de $\left(\mathrm{CoFe}_{2} \mathrm{O}_{4}\right)$ e $\left(\gamma-\mathrm{Fe}_{2} \mathrm{O}_{3}\right)$.

Neste trabalho, apresentamos um estudo que avalia a metodologia de determinação dos

$M$
$\dot{b}$
valores de
$2+\dot{i}$
$\dot{i}$
$\dot{i}$ , que são utilizados no cálculo da fração volumétrica em nanopartículas. As propriedades físico-químicas do nanocolóide, estudadas aqui, são investigadas utilizando diversas técnicas de caracterização. A caracterização estrutural é feita utilizando a técnica de difração de raios X. Para investigar a morfologia e a dispersão em tamanho destes materiais, utilizamos a técnica de Microscopia Eletrônica de Transmissão (MET); para a composição química das amostras utilizamos as técnica de dicromatometria e Espectrometria de Absorção Atômica (AAS); medidas de densidade em diferentes frações volumétricas em nanopartículas, utilizando um densímetro e uma balança de Arquimedes, são realizadas e comparadas.

Os resultados indicam que, apesar de as medidas de densidade utilizando os dois equipamentos apresentarem bom acordo, recomenda-se preferencialmente a utilização do densímetro digital para medidas de densidade em coloides não viscosos, e, por fim, a balança de Arquimedes será eficaz para a determinação de densidade de materiais coloidais muito viscosos. 
Palavras-chave: nanocolóide, nanopartículas, síntese, caracterização e densidade.

\begin{abstract}
Magnetic fluids or ferrofluids are colloidal dispersions of nanoparticles (NPs) of ferrite type in a liquid carrier of your choice. On these materials the way of expressing the concentration of nanoparticles is the volume fraction in NPs $\varphi$, given by the ratio between the total volume of particles and the volume of the dispersion. In the case of the magnetic fluids stabilized on aqueous acidic medium, the NPs are of core/shell type and in this work we have cobalt ferrite NPs (CoFe2O4) covered by a maghemite layer ( $y-\mathrm{Fe} 2 \mathrm{O} 3)$.

Recently a chemical model that takes into account a core/shell structure of nanoparticles was introduced in order to determine the $\varphi$ of ferrofluids samples. In this model, the volume fraction is calculated by using the molar concentrations of $\left(\mathrm{CoFe}_{2} \mathrm{O}_{4}\right)$ and $\left(\gamma-\mathrm{Fe}_{2} \mathrm{O}_{3} i\right.$. In this work we present a study that evaluates the methodology of determining the values of

$2+i$

$M^{i} \quad$ that are used to calculate the volumetric fraction of NPs. The physical chemical $\dot{i}$

properties of the nanocolloids studied here are investigated using various techniques of characterization. The structural characterization is carried out using the technique of $\mathrm{x}$ ray diffraction. To investigate the morphology and dispersion in size of these materials, we use the technique of Transmission Electron Microscopy (TEM). For the chemical composition of the samples we have used the dichromatometric tritation method and Atomic Absorption Spectroscopy (AAS). Density measurements at different volume fractions of nanoparticles, using a Density Meter and an Archimedes balance are performed and compared. The results indicate that, although the density measurements using the two devices are in good agreement, it is more recommended to use the digital Density Meter for density measurements in non viscous colloids and finally that the Archimedes Balance is more effective for density determination of very viscous colloidal materials.
\end{abstract}


Keywords: nanocolóide, nanoparticles, synthesis, characterization and density.

\section{LISTA DE FIGURAS}

Figura 1: Ferrofluido submetido a um campo magnético externo, criação de picos magnéticos. .3

Figura 2: Caminho da síntese de ferrofluido desde a coprecipitação até o final com a peptização.

Figura 3: Modelo de partícula núcleo/superfície, com o diâmetro $d_{c}$ compondo o core, e a espessura do shell sendo $e$. A razão entre as frações volumétricas fornecem o comprimento da camada de maghemita......8

Figura 4: Empacotamento atômico dos sítios tetraédricos $A$, e octaédricos $B$ presentes na célula unitária contendo metal divalente.

Figura 5: Difração de raios x aplicada em materiais cristalinos................................................................11 Figura 6: Microscópio eletrônico de transmissão Tecnai G2-Spirit - FEI - 2006, capacidade de resolução $0,34 \mathrm{~nm}$, aumento $22 \mathrm{x}$ a $300.000 \mathrm{x}$.

Figura 7: Espectrômetro de Absorção Atômica (AAS) Thermo SCIENTIFIC, modelo Solar S4.........................15

Figura 8: Esquema de funcionamento da absorção atômica. A luz emitida pela lâmpada de cátodo oco é dividida, os pulsos são recombinados após transpassarem os analitos vaporizados na chama. As linhas de emissão e absorção têm diferenças na largura dos picos, o sistema avalia a razão entre o log das intensidades, $\log \frac{P_{0}}{P}$

Figura 9: Aparelho DMA 38 ANTON PAAR, para medição de densidade e gravidade específica em função da temperatura ambiente.

Figura 10: Princípio da medida de densidade utilizando a balança de Arquimedes, em que constam os materiais usados: Balança, copos de medida, dodecano e o anteparo.

Figura 11: Difratogramas de raios x obtidos para amostras constituídas de ferrita de cobalto. A intensidade do

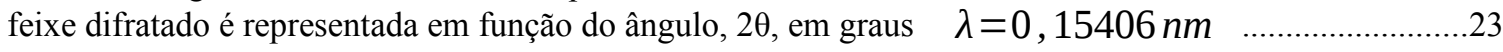

Figura 12: Imagem típica de micrografia para a amostra FG3 ..................................................................24

Figura 13: Histograma normalizado da distribuição de tamanhos das nanopartículas para a amostra FG3 ..........24

Figura 14: Imagem em alta resolução de uma partícula única para a amostra FG3 ..........................................26

Figura 15: Densidade do fluido magnético em função da fração volumétrica em material $\phi$...............................29

Figura 16: Densidade em função da fração volumétrica ( $\phi_{P} \quad$ ) media no densímetro. O detalhe mostra o ajuste dos dados experimentais com a expressão $\rho_{F F}=\rho_{S} \phi_{p}+\rho_{H_{2} O}\left(1-\phi_{p}\right)$

Figura 17: Densidade em função da fração volumétrica $\phi_{P}$ medidas na balança de Arquimedes. O detalhe mostra o ajuste dos dados experimentais com a expressão $\rho_{F F}=\rho_{S} \phi_{p}+\rho_{H_{2} O}\left(1-\phi_{p}\right)$

Figura 18: Comparação das densidades em função da fração volumétrica ( $\phi_{P}$ ) obtidas no densímetro e na balança de Arquimedes. O detalhe mostra o ajuste dos dados experimentais com a expressão $\rho_{F F}=\rho_{S} \phi_{p}+\rho_{H_{2} O}\left(1-\phi_{p}\right)$ 


\section{LISTA DE TABELAS}

Tabela 1: $\mathrm{d}_{\mathrm{rx}}$ - diâmetro cristalino determinado a partir da fórmula de Scherrer, $\langle\boldsymbol{a}\rangle$ : é o parâmetro de malha, $d_{0}$ : diâmetro característico, $\sigma$ : índice de polidispersão associado a uma distribuição do tipo log-normal e $d_{\text {calc }}^{r x}$ : diâmetro calculado a partir da relação, $d_{\text {calc }}^{r x}=\exp \left(2,5 \sigma^{2}\right),\langle\boldsymbol{d}\rangle$ : diâmetro médio das nanopartículas, $\quad d_{m p}::$ diâmetro mais provável.............................................................................25

$$
2+i \quad 3+i
$$

Tabela 2: $\mathrm{d}_{\mathrm{rx}}$ - diâmetro cristalino determinado à partir da fórmula de Scherrer, $C o^{i} \quad F e^{i}:$ são as $\dot{i} \quad e \dot{i}$

concentrações molares de cobalto e ferro respectivamente, $X_{m}$ : : é a fração molar em metal divalente, fração em volume da ferrita de cobalto no núcleo, fração em volume da maghemita na superfície, $e$ é a espessura da camada de maghemita, e/r é a razão entre a a espessura de maghemita e o raio da nanopartícula.

Tabela 3: $\quad \rho_{\gamma-\mathrm{Fe}_{2} \mathrm{O}_{3}}, \quad \rho_{\mathrm{CoFe}_{2} \mathrm{O}_{4}}$ - são as densidades da maghemita e da ferrita de cobalto do tipo bulk respectivamente retiradas de [32], $\rho_{\text {ajuste }}$ : a densidade da partícula retirada da equação $22, \quad \rho_{\text {Calc }} \quad:$ densidade calculada a partir da equação $12, \quad \rho_{\text {Calc } 1}:$ densidade calculada a partir da equação $\rho_{S}=\left(\frac{\phi_{S}}{\phi_{P}}\right) \rho_{\text {Shell }}+\left(\frac{\phi_{S}}{\phi_{P}}\right) \rho_{\text {Core }}$

Tabela 4: Densidades da água $\rho_{\mathrm{H}_{2} \mathrm{O}}$ e seus respectivos erros obtidos à partir dos diferentes métodos, balança de Arquimedes e Densímetro.

Tabela $5 \rho_{S}$ (Arquimedes) - é a densidade obtida a partir do ajuste da equação 22 utilizando a balança de Arquimedes, $\rho_{S}$ (DM38), $\quad \rho_{\text {Calc }}$ : é a densidade obtida a partir do ajuste da equação 22, utilizando o densímetro DM38, $\quad \rho_{\text {Calc1 }}:$ densidade calculada a partir da equação $\rho_{S}=\left(\frac{\phi_{S}}{\phi_{P}}\right) \rho_{\text {Shell }}+\left(\frac{\phi_{S}}{\phi_{P}}\right) \rho_{\text {Core }}$ 


\section{SUMÁRIO}

1. INTRODUÇÃO

2. FLUIDOS MAGNÉTICOS................................................................................13

2.1 Elaboração de ferrofluidos...............................................................................................15

2.2 Tratamento de superfície formação core-shell...........................................................17

2.3 Peptização...............................................................................................................17

2.4 Modelo núcleo/superfície de composição química.....................................................17

2.5 Estrutura cristalina de ferritas.............................................................................19

3. DESCRIÇÃO DAS TÉCNICAS DE CARACTERIZAÇÃO FÍSICO-QUÍMICA DE

FERROFLUIDO..................................................................................................................20

3.1 Difração de raios x.......................................................................................................................20

3.2 Microscopia eletrônica de transmissão (MET)..........................................................23

3.3 Dicromatometria...........................................................................................................24

3.4 Espectrometria de Absorção Atômica (AAS).........................................................25

3.5 Densidade de coloides magnéticos............................................................................27

3.6 Medida da densidade utilizando densímetro DMA 38 ANTON PAAR..................28

3.7 Princípio da medida.....................................................................................................28

3.8 Medidas da densidade das partículas utilizando balança de Arquimedes.............29

4. RESULTADOS OBTIDOS.........................................................................................33

4.1 Difração de raios x e Microscopia Eletrônica de Transmissão....................................33 
4.2 Composição Química da amostra FG3 ......................................................................37

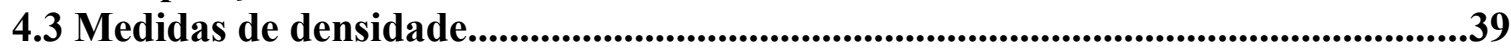

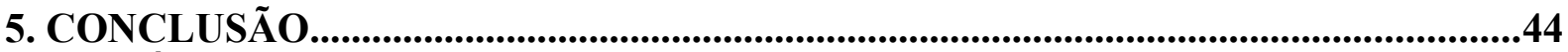

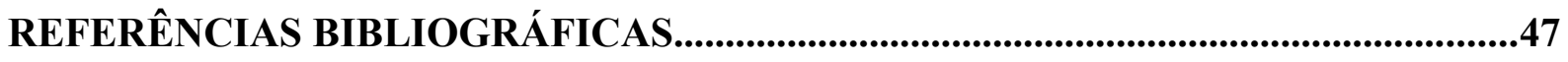




\section{INTRODUÇÃO}

A nanociência é a parte da ciência que lida com a manipulação da matéria em escala atômica e molecular. Essa ciência possibilita agir no interior da matéria, mudar sua estrutura alterando a disposição dos átomos que a compõe. $\mathrm{Na}$ atualidade, podemos encontrar aplicações das nanotecnologias em diversos campos de conhecimento, a saber: Biologia, Medicina, Informática, Comunicação, Segurança, Meio Ambiente, Materiais de Construção, Transportes. Dentro do contexto dessas nanotecnologias, temos as nanopartículas e nanocolóides magnéticos. Os nanocolóides magnéticos são dispersões ultraestáveis de nanoestruturas magnéticas em um líquido carreador específico, que pode ser a água ou outro material a escolha. Graças à conjunção original de propriedades líquidas e magnéticas, eles podem ser confinados, deslocados, deformados e controlados por aplicação de um campo magnético externo, e esta é a grande peculiaridade dos nanocolóides magnéticos em relação aos fluidos comuns. Outra peculiaridade desses materiais é a possibilidade de controlar a fração volumétrica em partículas. A fração volumétrica em partículas, $\phi_{P}$, pode ser definida como a razão entre o somatório do volume de todas as nanopartículas pelo volume total do ferrofluido. A determinação dessa fração volumétrica pode ser realizada através de técnicas de dosagem química, tais como a dicromatometria e a espectrometria de absorção atômica (AAS). Outro aspecto importante, é a determinação da densidade nos ferrofluidos. Para cada valor da fração volumétrica, existe um valor de densidade associado. Desta forma, o objetivo central desta pesquisa é avaliar os parâmetros de determinação da fração volumétrica em nanopartículas para o ferrofluido. Nesse contexto, sintetizamos nanopartículas magnéticas do tipo núcleo/superfície, à base de ferrita de cobalto $\left(\mathrm{CoFe}_{2} \mathrm{O}_{4}\right)$ recobertos por uma camada externa de maghemita $\left(\gamma-\mathrm{Fe}_{2} \mathrm{O}_{3}\right)$.

A primeira sessão inicia-se com o histórico das técnicas de obtenção de ferrofluido. Sua evolução, a partir do século XX, resulta do amplo aparato teórico embasado pela física moderna. Aqui, estão expostas as razões pelas quais é possível atingir a estabilidade coloidal, tratadas em termos de equilíbrio de forças, sendo estas: a eletromagnética e a gravitacional, que desempenham papel fundamental na estabilidade das dispersões com nanopartículas magnéticas. Abordamos, ainda, os processos e métodos envolvidos na elaboração de nanocolóides magnéticos. 
Em seguida, tem-se a abordagem dos métodos teóricos utilizados nos processos de caracterização estrutural, morfológicas e composição química dos materiais obtidos. Para a caracterização estrutural das nanopartículas magnéticas, utilizamos a técnica de difração de raios $\mathrm{x}$, que permite determinar o tamanho médio das nanopartículas. No que tange à morfologia destes materiais, utilizamos um microscópio eletrônico de transmissão. A partir da contagem das imagens obtidas, é possível verificar que, de fato, existe uma distribuição em tamanhos dessas nanopartículas e elas possuem um formato aproximadamente esférico. Já a parte da composição química dos materiais estudados neste trabalho, utilizamos técnicas de dosagens como a dicromatometria e a espectrometria de absorção de força atômica. Esses métodos permitiram avaliar a fração volumétrica de metais divalentes que, no nosso caso, é o $\mathrm{Co}^{2+} \mathrm{e} \mathrm{o} \mathrm{Fe}^{3+}$.

Posteriormente, tratamos a metodologia aplicada para a determinação de densidades das amostras para diversas frações volumétricas variando desde regimes diluídos até concentrados $(0,007$ a 9,6\%). Para tanto, utilizamos dois tipos de equipamento: um densímetro comercial e uma balança de Arquimedes fabricada por nós. Para o caso da balança de Arquimedes, explicamos a metodologia empregada, avaliamos os fatores que interferiram na precisão do equipamento e todo o material utilizado, durante o processo. Os resultados obtidos são apresentados na última seção.

\section{FLUIDOS MAGNÉTICOS}

Em nossa contemporaneidade, os sistemas coloidais são considerados um dos principais campos de estudo e de aplicação em diversas áreas, tais como: Ciências de Materiais, Nanobiotecnologia, Física, Química, dentre outras. Contudo, sua origem remonta meados do século XVIII, quando Wilson propôs a técnica de moagem de ferro, visando produzir pós deste e usá-los em meios líquidos para criar dispersões [1].

Iniciou-se, desde então, a pesquisa com nanopartículas em meios fluídicos dispersões em meios gasosos, oléicos e aquosos. Porém, não houve bons resultados por conta do desconhecimento relacionado à variedade de forças e fatores envolvidos na estabilidade de tais sistemas. Ao longo dos séculos seguintes, a evolução científica, desdobradas pelo eletromagnetismo, física estatística e física moderna, expandiu 
também o campo de estudo e a compreensão para sistemas brownianos - difusão de partículas.

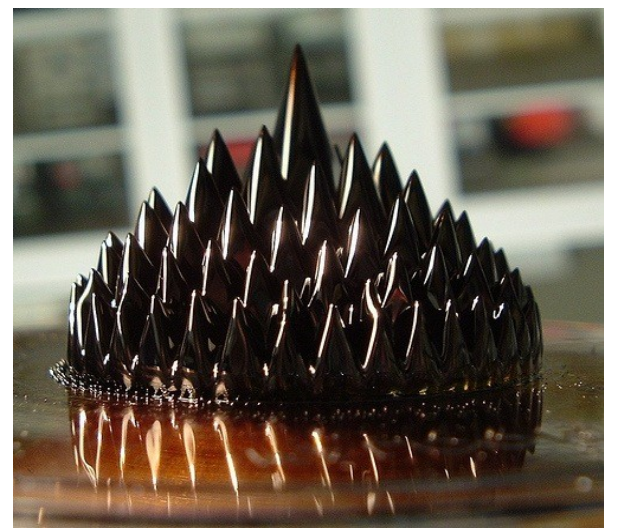

Figura 1: Ferrofluido submetido a um campo magnético externo, criação de picos magnéticos.

Fonte: http://www.taringa.net/posts/hazlo-tu-mismo/17549472/Dos-metodos-de-fabricar-ferrofluido-postmejorado.html

No ano de 1930, retomaram-se as pesquisas destes sistemas complexos. Sua evolução deveu-se à melhoria das técnicas de obtenção das nanopartículas. A partir de então, novos modelos teóricos foram propostos. Como consequência, houve o aumento na compreensão das forças interativas envolvidas nesse processo. Ademais, a evolução científica resultou no avanço do conhecimento atômico e no desenvolvimento tecnológico.

No ano 1965, com o advento da era espacial, a ciência coloidal mostrou sua força de aplicabilidade, quando nanopartículas foram sintetizadas e dispostas em combustível para foguetes [2]. É sabido que no espaço o deslocamento dos fluidos é comprometido com a aparente ausência de gravidade, enquanto que, sob influência da mesma, a pressão é responsável pelo escoamento [3].

Por conseguinte, a fluidez do combustível em estado de microgravidade não ocorre devido à ausência de pressão. Desta forma, os fluidos magnéticos ganharam espaço pela sua sensibilidade a campos magnéticos aplicados, o que de fato possibilitou o deslocamento do combustível no espaço.

Os ferrofluidos englobam diversas áreas de pesquisa por sua versatilidade, pois quando submetidos a campos magnéticos, seu uso mostra-se eficaz na camuflagem de aviões anti-radares - justamente pela capacidade de absorção da radiação eletromagnética na faixa de micro-ondas. Desde os anos 50, a inovação tecnológica 
advinda de aplicações bélicas corresponde a $80 \%$ das pesquisas em países como Estados Unidos e Rússia. O uso de ferrofluidos para sistemas de som, alto-falantes, tem aplicabilidade se usados na dissipação de energia térmica (Figura 1).

Em sistemas de medida de alta precisão como balanças, indispensáveis em química, os ferrofluidos também foram aplicados para diminuição das oscilações indesejáveis - amortecimento crítico - para obter-se boa precisão em medidas de massa da ordem microgramas.

A capacidade das partículas coloidais em adsorverem detritos e metais pesados tem apresentado grande eficiência [4]. Um dos maiores impactos dessa inovação tem sido o tratamento contra câncer, em que as nanopartículas podem ser revestidas por radioisótopo e o tratamento radioterápico, em fase experimental, tem-se tornado menos invasivo - concentração em pontos isolados com aplicação de campos magnéticos localizados $[5,6]$.

\subsection{Elaboração de ferrofluidos}

Para garantir a estabilidade coloidal de um ferrofluido, é de fundamental importância a obtenção de partículas com dimensões nanométricas tipicamente menores de uma dezena de nanômetros, para o caso das ferritas. Visto que, tais sistemas são dispersões que ocorrem em meios líquidos, portanto devem ter tamanhos adequados para que a força gravitacional seja compensada pela agitação térmica responsáveis pelo movimento browniano, movimento caótico sem direção privilegiada, presente em meios fluídicos .

Existem duas técnicas para obtenção de partículas em nanoescala que satisfazem esses requisitos, sendo de suma importância o controle do processo de produção para obtê-las em: dimensões ideais, estabilidade estrutural, estabilidade química, baixa polidispersão e elevada cristalinidade. São elas: top-down e bottom-up $[7,8]$.

A obtenção de nanopartículas pela técnica top-down advém geralmente da moagem de metais como ferro, nas quais limalhas são exaustivamente pressionadas e atritadas. Contudo, esse processo desprende muito tempo e são, em geral, muito onerosos se comparados a métodos mais modernos. 
Já na síntese do tipo bottom-up, o processo ocorre a partir dos íons metálicos em meio aquoso, ou em outro solvente, e os cristais se formam e crescem até atingir o tamanho em nanoescala. Nesta metodologia, processos de nucleação e crescimento cristalino competem para determinar o tamanho médio e a polidispersão das nanopartículas.

O processo de síntese de um fluido magnético descrito em detalhe em [9] é composto basicamente por 3 etapas: obtenção das nanopartículas, utilizando um método bottom-up; tratamento químico da superfície e; peptização no meio aquoso. $\mathrm{O}$ processo pode ser resumido pelo esquema abaixo (Figura 2).

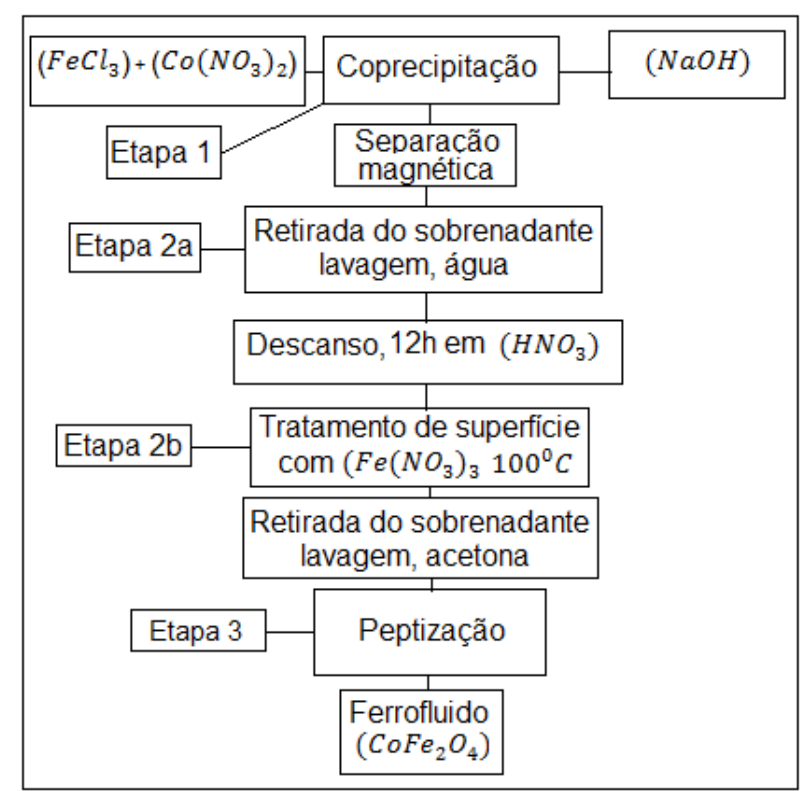

Figura 2: Caminho da síntese de ferrofluido desde a coprecipitação até o final com a peptização.

A síntese das nanopartículas de ferritas começa com uma reação de coprecipitação de uma mistura de sais de metais na proporção estequiométrica da ferrita. A reação global para síntese de $\mathrm{CoFe}_{2} \mathrm{O}_{4}$ pode ser expressa da seguinte maneira:

$$
\begin{gathered}
-i(a q) \rightarrow \mathrm{Co} \mathrm{Fe}_{2} \mathrm{O}_{4}(\mathrm{~s})+4 \mathrm{H}_{2} \mathrm{O} \\
3+i(a q)+8 \mathrm{OH}^{i} \\
\mathrm{Co}^{+2}(a q)+2 \mathrm{Fe}^{i}
\end{gathered}
$$


Durante o processo de coprecipitação, pode-se controlar o crescimento do cristal e, consequentemente, o diâmetro das nanopartículas obtidas. Como vimos acima, dois processos governam a síntese de um precipitado cristalino: a nucleação e o crescimento cristalino. Apesar de ocorrerem concomitantemente, as taxas relativas em que esses processos ocorrem determinam o diâmetro final da partícula. Dessa maneira, o aumento da supersaturação relativa beneficia o processo de nucleação e a formação de partículas menores. Já uma diminuição na supersaturação relativa favorece o crescimento cristalino, originando partículas com maior diâmetro. Assim, pelo controle de parâmetros como pH, temperatura, natureza da base, agitação da mistura de reação, concentração e velocidade de adição dos reagentes, é possível favorecer um ou outro

processo, obtendo, assim, diâmetros específicos que podem variar de 2 até $30 \mathrm{~nm}$.

\subsection{Tratamento de superfície formação core-shell}

As nanopartículas então obtidas se encontram em um meio fortemente alcalino e estão carregadas negativamente. Assim, realizamos lavagens das partículas com água, reduzindo-se, ao máximo, o volume de sobrenadante, visando remover o excesso de co-íons e contra-íons do meio. Em seguida, o sistema é acidificado com ácido nítrico $\left(\mathrm{HNO}_{3}\right) 2 \mathrm{~mol} / \mathrm{L}$ e deixado em repouso por 12 horas, em média. Após o repouso, o excesso de ácido é removido e as partículas são novamente lavadas com água.

Entretanto, apesar das partículas estarem carregadas positivamente, essas não são termodinamicamente estáveis para serem dispersas em meio ácido. Isso significa que as nanopartículas degradam-se espontaneamente com o tempo, processo favorecido em baixos valores de $\mathrm{pH}$. Assim, é introduzido um tratamento empírico, inspirado na síntese de maghemita, que consiste em aquecer a $100{ }^{\circ} \mathrm{C}$ por 30 minutos a solução contendo as partículas na presença de nitrato férrico $\mathrm{Fe}\left(\mathrm{NO}_{3}\right)_{3}$. Esse processo introduz uma quebra de homogeneidade na composição química da nanopartícula, associada a um "enriquecimento" em ferro da camada superficial com composição média do tipo ( $\gamma-\mathrm{Fe}_{2} \mathrm{O}_{3}$.). A nanopartícula, então, é estável frente a ataques ácidos e, juntamente com o núcleo de $\left(\mathrm{CoFe}_{2} \mathrm{O}_{4}\right)$, constitui a base para o modelo recentemente proposto de composição química do tipo core-shell, conforme apresentado no item 2.4, seção 2. 


\subsection{Peptização}

O processo pelo qual se dá a finalização da síntese é chamado de peptização e consiste em controlar a força iônica, após o tratamento com $\mathrm{Fe}\left(\mathrm{NO}_{3}\right)_{3}$. Para obtermos soluções coloidais estáveis, é preciso realizar sucessivas lavagens para diminuir a força iônica. As partículas são agitadas dentro de uma mistura água/acetona e, em seguida, decantadas sobre uma placa magnética antes da aspiração do sobrenadante. Após vários tratamentos, a força iônica é suficientemente pequena para permitir a dispersão dos nanocristais dentro de uma solução de $\mathrm{pH}$ aproximadamente 2.

\subsection{Modelo núcleo/superfície de composição química}

Conforme abordamos anteriormente, após a etapa 1 de síntese, as nanopartículas sintetizadas são dispersas em meio ácido. A dissolução dessas partículas é evitada graças a uma estratégia "núcleo superfície" que permite proteger as partículas da dissolução em baixo $\mathrm{pH}$. Entretanto, o método utilizado que descrevemos nas etapas $2 \mathrm{a}$ e $2 \mathrm{~b}$, do esquema da síntese, ocasiona um enriquecimento com ferro de suas superfícies, o que é interpretado através da formação de um modelo de composição química núcleo-superfície [9]. Mais especificamente, para as nanopartículas estudadas neste trabalho, temos um núcleo formado por uma ferrita de cobalto $\left(\mathrm{CoFe}_{2} \mathrm{O}_{4}\right)$ recoberta por uma camada superficial de maghemita ( $\left.\gamma-\mathrm{Fe}_{2} \mathrm{O}_{3}\right)$. Os cálculos que descrevem a camada interna e externa da nanopartícula, segundo a proporção de cada elemento, as dividem em duas frações volumétricas, quais sejam:

$\phi_{\text {core e }} \phi_{\text {shell }}$. Desta forma, o volume total da nanopartícula é resultado da soma das frações volumétricas das partes constituintes. A equação abaixo exemplifica essas distribuições de maneira mais clara.

$$
\phi_{p}=\phi_{c}+\phi_{s}
$$




$$
\begin{gathered}
2+i \\
M^{i} \\
\dot{i} \\
\phi_{c}=i \\
\\
\\
3+\dot{i} \\
F e^{i} \\
\dot{i} \\
2+i \\
M^{i} \\
-2[\dot{i}) V_{M}^{S} \\
\dot{i} \\
\phi_{s}=i
\end{gathered}
$$

Conforme descrito na equação, $\begin{gathered}2+i \\ M^{i}\end{gathered}$ é a quantidade molar de metal divalente; $\begin{gathered}3+i \\ F e^{i}\end{gathered}$ a quantidade molar de ferro; $\quad V_{M}^{C}$ e $\quad V_{M}^{S} \quad$ o volume molar do núcleo e da superfície, respectivamente. $\mathrm{O}$ volume molar do core é $43,53 \cdot 10^{-3} \mathrm{~L} / \mathrm{mol}$ para o cobalto e $31,47.10^{-3} \mathrm{~L} / \mathrm{mol}$ para a maghemita $\left(\gamma-\mathrm{Fe}_{2} \mathrm{O}_{3}\right)$. A figura 4 apresenta as partes que constituem a nanopartícula. Conhecido o diâmetro da mesma, pela técnica de raios x, pode-se estimar a espessura

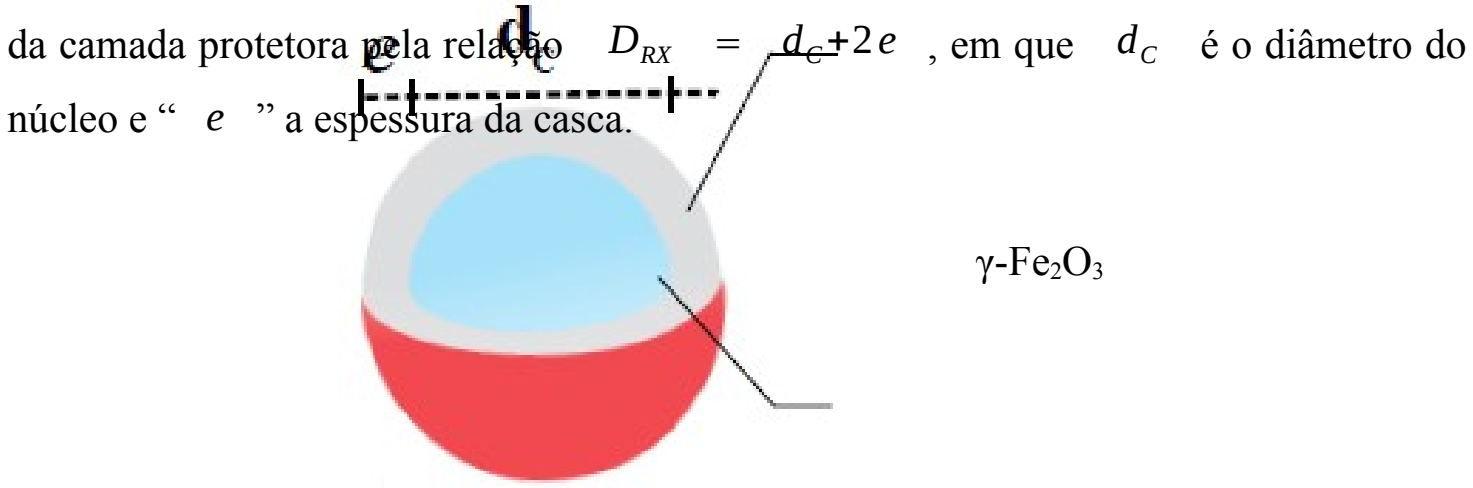
$\mathrm{CoFe}_{2} \mathrm{O}_{4}$

Figura 3: Modelo de partícula núcleo/superfície, com o diâmetro $\quad D_{c} \quad$ compondo o core, e a espessura do shell sendo $e$. A razão entre as frações volumétricas fornecem o comprimento da camada de maghemita.

Fonte: SILVA, F. G. da. Propriedades magnéticas, desordem de superfície e polarização por intercâmbio de nanopartículas magnéticas. 2013. 149 f. Tese (Doutorado) - Universidade de Brasília, Université Pierre et Marie Curie, Paris VI, 2013. 


\subsection{Estrutura cristalina de ferritas}

A estrutura interna das ferritas, que constituem os fluidos magnéticos, é composta por uma rede cristalina de átomos que se organiza como a do espinélio, em referência ao composto $\left(\mathrm{Mg} \mathrm{Al}_{2} \mathrm{O}_{4}\right)$ encontrado na natureza como mineral. Se um dos cátions metálicos for o ferro trivalente $\mathrm{Fe}^{3+}$, estes materiais serão chamados de ferritas. Nas cadeias atômicas que as compõem estão presentes metais divalentes de transição, tais como

$$
\begin{aligned}
& \begin{array}{c}
2+i, \mathrm{Cu}^{+2}, i^{+2}, \mathrm{Zn}^{+2} \\
\mathrm{Co}^{+2}, \mathrm{Mn}^{i}
\end{array} \text { o ferro } \begin{array}{r}
3+i \\
\mathrm{Fe}^{i}
\end{array} \text { e oxigênio. Sua fórmula geral é designada por } \\
& 2+i \mathrm{Fe}_{2} \mathrm{O}_{4} \\
& \begin{array}{c}
M^{i} \\
i
\end{array} \text {, no caso estudado } \begin{array}{c}
2+i i C o^{i} \\
M^{i}
\end{array} \text {. Tal estrutura é organizada pelo }
\end{aligned}
$$

empacotamento de 32 átomos de oxigênio ligados ao ferro e ao metal divalente, tendo a forma cúbica de face centrada. Dessa forma, são criados 64 interstícios com simetria tetraédrica que são designados por convenção pela letra $A$, e 32 interstícios com simetria octaédrica designados pela letra $B$. A distribuição catiônica dos metais, dentro desses sítios, seguem a proporção $1 / 8$ de interstícios tetraédricos e 1/2 octaédricos (Figura 4).

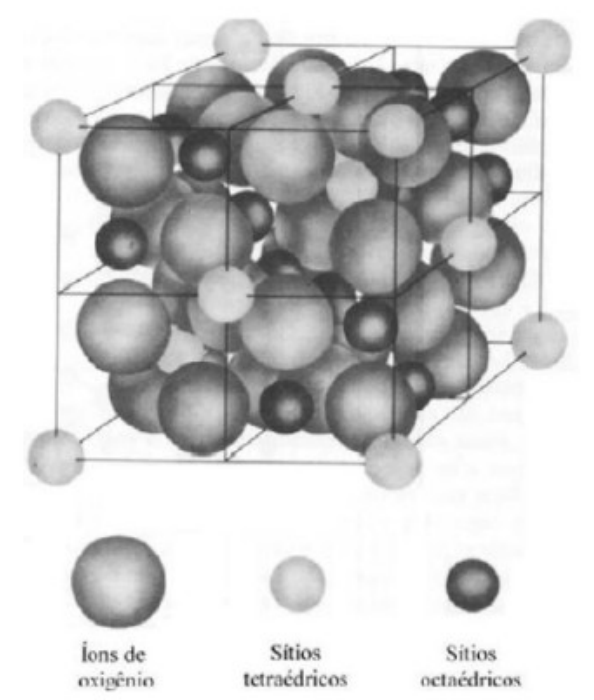

Figura 4: Empacotamento atômico dos sítios tetraédricos $A$, e octaédricos $B$ presentes na célula unitária contendo metal divalente.

Fonte: FIGUEIREDO, L. C. Sistemas magnéticos nanoparticulados à base de maghemita. $2009.121 \mathrm{f}$. Dissertação (Mestrado) - Universidade de Brasília, Instituto de Física, 2009, p. 26. 
A estrutura do espinélio pode ser dividida em diretos, inversos e mistos. E segue a forma cristalográfica apresentada abaixo, com a presença dos cátions divalentes, tanto em $A$ quanto em $B$,

$$
\begin{gathered}
3+i \\
2+i F e_{x}^{i} \\
M_{(1-x)}^{i} \\
\dot{i} \\
2+i \\
3+i M_{x}^{i} \\
F e_{(2-x)}^{i} \\
\dot{i} \\
2-i \\
\dot{i} \\
\dot{i} \\
\dot{i}
\end{gathered}
$$

em que $x$ é a posição ocupada pelos íons metálicos, sendo a fração dos sítios tetraédricos compostos por $\begin{gathered}3+i \\ F e^{i}\end{gathered}$. Quando um dos cátions da composição é o ferro trivalente, $\begin{gathered}3+i \\ F e^{i}\end{gathered}$, o ferrofluido é chamado de ferrita, no presente trabalho em que foi estudada a ferrita de cobalto.

A posição $x$ ocupada pelos íons divalentes define a classificação do espinélio, sendo normal ou direto quando todos estes íons ocuparem os sítios tetraédricos, $x=0$. Por outro lado, quando os íons divalentes ocupam sítios octaédricos, os espinélios são classificados como do tipo inverso. Já espinélios do tipo misto apresentam valores de $\mathrm{x}$ entre 0 e 1 .

\section{DESCRIÇÃO DAS TÉCNICAS DE CARACTERIZAÇÃO FÍSICO-QUÍMICA DE FERROFLUIDO}

\subsection{Difração de raios $x$}

Uma técnica bastante empregada na caracterização estrutural de materiais é a técnica de difração de raios $\mathrm{x}$. A sua descoberta se deu no final do século XIX, por 
Röntgen, e seu uso foi largamente aplicado na análise da constituição de materiais, através de figuras de interferência.

Conhecendo a natureza do cristal, que servirá como filtro - com os valores tabelados -, separam-se os comprimentos de onda pré-selecionados que emergem, para que o comprimento de onda monocromático do feixe difratado incida sobre qualquer amostra, a qual se queira estudar. Portanto, cada sólido cristalino possui um padrão característico de difração de raios $\mathrm{x}$, que pode ser usado para determinar a sua estrutura, ou seja, como os átomos se empacotam juntos em um estado cristalino, sua distância interatômica, seu ângulo, tamanho e a forma de uma unidade de célula para um determinado composto [10].

A determinação da estrutura cristalina, por meio de raios $\mathrm{X}$, usa exatamente esse processo difratório. Com efeito, a relação entre a intensidade espalhada, o ângulo $2 \theta$ e tempo de contagem produzem picos de interferência, os quais são comparados com dados catalogados pelo ICDD (International Institute of Diffraction Data).

Experiências semelhantes às de Thomas Young, aplicadas ao estudo da faixa espectral (difração e interferência), utilizaram comprimentos de luz na faixa espectral visível, incididas em pequenas fendas, gerando o fenômeno da difração.

O processo inverso, no qual já se tenham vários comprimentos de onda determinados, pode mostrar exatamente o tamanho das fendas e suas distâncias. Em redes cristalinas compostas por metais, são visualizadas tanto as distâncias entre cada átomo e seus vizinhos, quanto entre os planos de acomodação.

O fenômeno da difração ocorre quando o tamanho das fendas é inferior ou da ordem do comprimento de onda incidente. O resultado é a divergência dos raios luminosos e formação de figuras pontuais em um anteparo - distante aproximadamente 2 metros da amostra - espacialmente posicionado.

Como o raios x possui altos valores de energia na faixa de 10 à $100 \mathrm{Kv}$, seus comprimentos de onda $\lambda$ variam entre $1 a ̀ 10 \AA$. Tal comprimento é dado pela relação entre a frequência, velocidade da luz e constante de Planck (Equação 6).

$$
\lambda=h c / v
$$


Os feixes de radiação, com essa ordem de energia, possuem alto poder de penetração. Von Laue propôs que se cristais fossem usados para conseguir pequenas fendas difratarias da ordem de $1 \AA$, sua estrutura interna poderia ser visualizada.

Através da fórmula matemática conhecida como espaço recíproco (Equação 7), as redes cristalinas são descritas pelo modelo de Bravais, portanto, possuem periodicidade em suas estruturas [11].

$$
G=h A+k B+l C
$$

$$
A=2 \pi \frac{b \times c}{a \cdot b \times c} \quad, \quad B=2 \pi \frac{c \times a}{a \cdot b \times c} \quad, \quad C=2 \pi \frac{a \times b}{a \cdot b \times c}
$$

(8)

Conforme exemplificado na equação acima, os fatores $h, k$ e $l$ são conhecidos como índices de Miller; $a, b$ e $c$ são os parâmetros de rede, distância entre cada átomo vizinho posicionados em um plano cartesiano tridimensional.

A determinação das distâncias interplanares e as formas das células primitivas surgem a partir desses índices. O instituto ICDD possui uma série de elementos tabelados, os quais podem ser comparados com dados obtidos de amostras que estejam sendo estudadas. A relação entre o ângulo de difração $\theta$, o comprimento de onda da radiação $\lambda$ e as distâncias interplanares $d_{h k l}$ da estrutura são dadas pela lei de Bragg [12]:

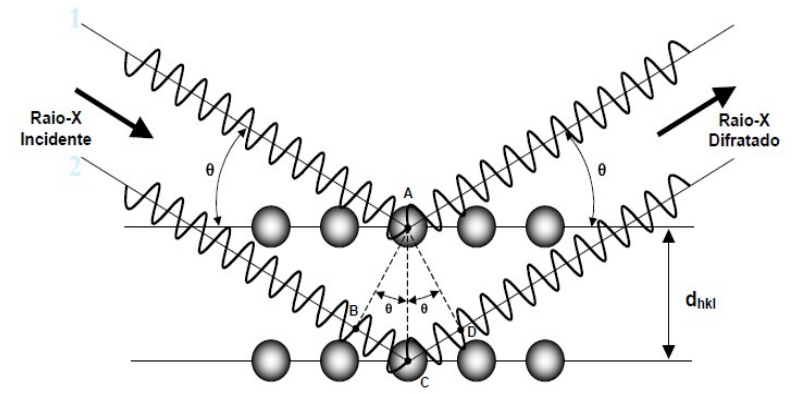

Figura 5: Difração de raios x aplicada em materiais cristalinos.

Fonte: CARAM, Rubens. Apostila Estrutura e propriedade dos materiais análise da estrutura cristalina. Campinas: UNICAMP, s/d. 


$$
2 d_{h k l} \operatorname{sen} \theta=n \lambda
$$

O fator $d_{h k l}$ refere-se às distâncias entre cada um dos planos dentro da estrutura. Os coeficientes $h k l$ são conhecidos como os índices de Miller e caracterizam o tipo de ordenamento atômico que compõe a rede cristalina.

A determinação das distâncias interatômicas se dá pela análise dos picos de interferência comparados aos padrões tabelados pelo ICDD. Cada grupo tabelado possui uma família $h k l$ que o caracteriza, portanto, pequenas divergências são notadas após a análise, advindas de ruídos de fundo e oscilações termodinâmicas. A estrutura atômica corresponde ao espinélio, tem formato cúbico e pode ser determinada de maneira simplificada pela relação $\quad d_{h k l}=\frac{a}{\sqrt{h^{2}+k^{2}+l^{2}}}$, onde $a$ refere-se ao vetor unitário que compõe a malha dentro das redes cristalinas.

\subsection{Microscopia eletrônica de transmissão (MET)}

A técnica de microscopia eletrônica de transmissão é um método que utiliza elétrons acelerados por uma diferença de potencial da ordem de $100 \mathrm{kV}$, dentro de um tubo com baixa pressão $10^{-5} \mathrm{mmHg}$. O grau de ampliação de imagem, por meio desta técnica, é da ordem de 1000 a 300.000 vezes.

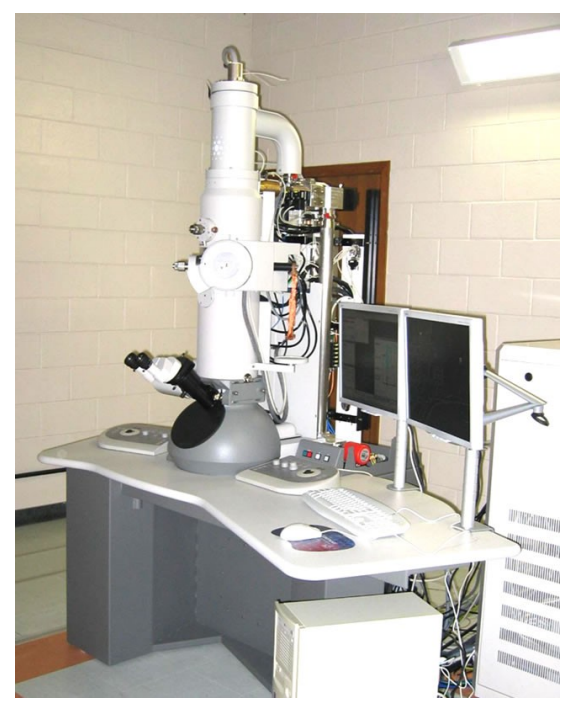

Figura 6: Microscópio eletrônico de transmissão Tecnai G2-Spirit - FEI - 2006, capacidade de resolução $0,34 \mathrm{~nm}$, aumento $22 \mathrm{x}$ a $300.000 \mathrm{x}$. 
Fonte: https://www.ufmg.br/microscopia/index.php?option=com frontpage\&Itemid=1

Os elétrons, os quais possuem comportamento onda/partícula, são direcionados ao encontro da amostra por uma série de lentes magnéticas que possibilitam a criação de um feixe concentrado e paralelo. Ao incidirem sobre a superfície de uma amostra, neste caso ferrita de cobalto, o feixe de onda de matéria sofre difração, desde que obedeça à lei de Bragg para baixos ângulos de incidência.

O conjunto de lentes magnéticas posicionadas entre o componente emissor e a amostra cria a condição necessária para penetração da radiação corpuscular sobre uma pequena área, e a onda de matéria emergente é novamente filtrada por um diafragma que bloqueia o excesso do feixe difratado. Novas lentes são utilizadas após a passagem do feixe pela amostra para ampliar a imagem das franjas de interferência. Os padrões das figuras pontuais ou figuras contendo círculos concêntricos determina a forma estrutural estuda.

A técnica de microscopia eletrônica de transmissão permite o estudo de materiais com defeitos estruturais, fases internas, defeitos de empilhamento, rupturas em ligas metálicas e, até mesmo, visualização das distâncias interplanares em materiais nanoestruturados.

\subsection{Dicromatometria}

A dicromatometria é uma técnica clássica de titulação utilizada em Química analítica. A solução de dicromato de potássio $\left(\mathrm{K}_{2} \mathrm{Cr}_{2} \mathrm{O}_{7}\right)$ é utilizada como agente oxidante para determinação de substâncias presentes na forma reduzida na amostra a ser analisada. $\mathrm{O}$ cátion ferroso $\mathrm{Fe}^{2+}$ ó o principal elemento determinado nesta técnica. Este método pode ser empregado para a determinação de ferro total em minérios. A amostra é dissolvida em ácido clorídrico ( $\mathrm{HCl} \dot{\zeta}$ e obtemos uma solução que contem ferro na forma $\mathrm{Fe}^{3+}$. Após esta etapa emprega-se então uma solução redutora que muda o estado de oxidação do ferro para $\mathrm{Fe}^{2+}$, o qual será titulado pela solução padrão de dicromato. As titulações em dicromatometria exigem o uso de indicadores de oxirredução, tais como, difenilamina em ácido sulfúrico e a difenilamina-sulfonato de sódio em solução aquosa. Essas substancias em presença de um agente oxidante qualquer transformam-se em cor violeta. Abaixo, descrevemos o processo utilizado para a determinação da concentração molar em ferro utilizando a técnica de titulação 
por dicromatometria. Esse procedimento foi realizado em triplicata, são retirados $100 \mu \mathrm{l}$ de ferrofluido, que é dissolvido em $10 \mathrm{ml}$ de ácido clorídrico sob aquecimento a $100^{\circ} \mathrm{C}$.

Após a ebulição, acrescenta-se o indicador cloreto estanoso $\left(\mathrm{SnCl}_{2}\right)$, para se obter uma coloração do verde escuro para o amarelo. Tal etapa é associada à redução de todo o ferro a $\begin{array}{cc}2+i \\ F e^{i}\end{array}$. Em seguida, a amostra é resfriada e acrescenta-se $\quad 10 \mathrm{ml}$ de cloreto mercuroso $\left(\mathrm{HgCl}_{2}\right)$ com agitação, até surgir uma coloração perolada na solução. Esta adição retira o excesso de $\begin{gathered}2+i \\ S n^{i}\end{gathered}$ em solução. Na sequência, acrescentase $5 \mathrm{ml}$ de ácido fosfórico $\left(\mathrm{H}_{3} \mathrm{PO}_{4}\right)$, com mais $2 \mathrm{ml}$ de ácido sulfúrico $\left(\mathrm{H}_{2} \mathrm{SO}_{4}\right)$ e 8 gotas de difenilamina sulfonato de sódio e a alíquota é titulada por solução de $\mathrm{K}_{2} \mathrm{Cr}_{2} \mathrm{O}_{7}, 1 \mathrm{M}$ que é um padrão primário.

A adição de ácido clorídrico ocasiona a obtenção de ferro na forma $\begin{gathered}3+i \\ F e^{i}\end{gathered}$. Por outro lado, o indicador estanho tem o papel de reduzi-lo para $\begin{gathered}2+i \\ F e^{i}\end{gathered}$. Essa redução finaliza-se quando a coloração da solução torna-se amarelada. O excesso de estanho $\frac{2+i}{S n^{i}}$ é retirado após o acréscimo na solução de cloreto mercuroso.

O mercúrio é, em seguida, reduzido a $\stackrel{+i}{\mathrm{Hg}^{i}}$ se estiver em temperatura ambiente. Isto ocorre, para evitar a formação de mercúrio metálico. Por fim, o ferro que se encontra na forma $\begin{gathered}2+i \\ F e^{i}\end{gathered}$ é titulado com a solução de dicromato de potássio $\left(\mathrm{K}_{2} \mathrm{Cr}_{2} \mathrm{O}_{7}\right)$, que o oxida novamente para $\begin{gathered}3+i \\ \mathrm{Fe}\end{gathered}$ sulfonato de sódio, junto com o ácido fosfórico complexa o $\begin{gathered}3+i \\ F^{i}\end{gathered}$, que tem a possibilidade de reagir com a difenilamina.

O processo de titulação se dá com a adição gota a gota de dicromato de potássio até o aparecimento da cor roxa na solução. Após o conhecimento do volume de dicromato utilizado, é feita a média aritmética entre as três amostras. Pode-se, então, seguir para os cálculos da concentração de ferro. 


$$
C_{F e}=\left[6\left(\operatorname{Vol}_{\text {méd }} \cdot C_{1}\right)\right] / \operatorname{Vol}_{\text {amost }}
$$

(10)

A Equação 10 fornece a concentração molar de ferro, com base na relação do volume médio de dicromato de potássio com a concentração molar do mesmo usado na titulação da amostra divididos pelo volume da amostra.

A concentração molar de ferro, pertencente à amostra estudada neste trabalho, foi portanto $5,52 \mathrm{~mol} / \mathrm{l}$.

\subsection{Espectrometria de Absorção Atômica (AAS)}

O estudo da composição química de nanopartículas magnéticas pode ser efetuado através da técnica de Espectrometria de Absorção Atômica (AAS). Tal método foi proposto, primeiramente, por Walsh, Alkemade e Milatz, nos anos 50 [13].

Sua popularização deve-se ao baixo custo de operação, fácil manuseio e alto grau de sensibilidade. A técnica é baseada na estimulação elétrica e térmica de materiais - elementos químicos específicos que compõem uma lâmpada de emissão. Um cátodo, devidamente selecionado, emite fótons com comprimento de onda $\lambda_{\text {cát }}$ característico, proveniente de um material com nível energético conhecido.

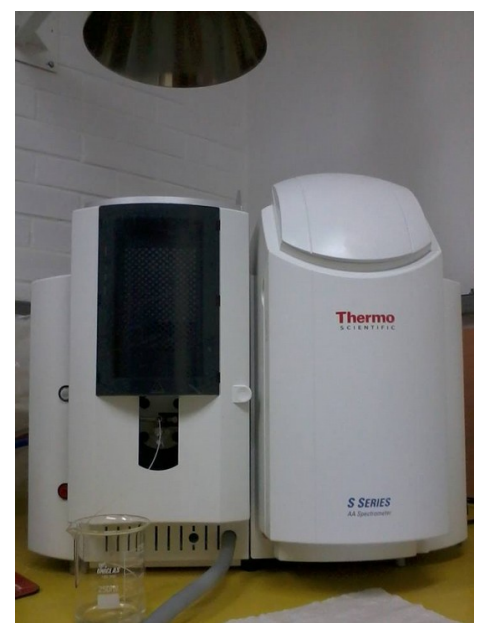

Figura 7: Espectrômetro de Absorção Atômica (AAS) Thermo SCIENTIFIC, modelo Solar S4.

O feixe que emerge da fonte é modulado por um disco recortador contendo um espelho semi-refletor. Parte da radiação eletromagnética emitida passa por um 
queimador (atomizador) de alta temperatura, enquanto a outra parte é utilizada como feixe de referência.

As duas fontes de emissão combinam-se nesse processo, produzindo um padrão de interferência: a primeira pertencente à lâmpada e a segunda pertencente aos analitos aquecidos. A largura do comprimento de onda emitido pela lâmpada é extremamente fino, da ordem de 0,002 a 0,005 $\mathrm{nm}$, enquanto que a largura da banda de absorção dos materiais vaporizados é superior. Quando ambos os feixes se recompõem, geram um padrão de interferência que é analisado através de uma função $\log \frac{P_{0}}{P}$ relacionada à razão entre ambas as fontes de radiação eletromagnética.

A interferência produzida por esse método é direcionada a um detector que gera duas correntes: uma contínua, originada pela chama e; outra alternada, proveniente do feixe original modulado. Um processador separa os dois sinais enviando, assim, somente os dados da corrente alternada para um computador que mostra a absorbância. Com essa técnica, utilizando lâmpadas específicas, é possível detectar mais de 70 elementos químicos e mais de 22 metais.

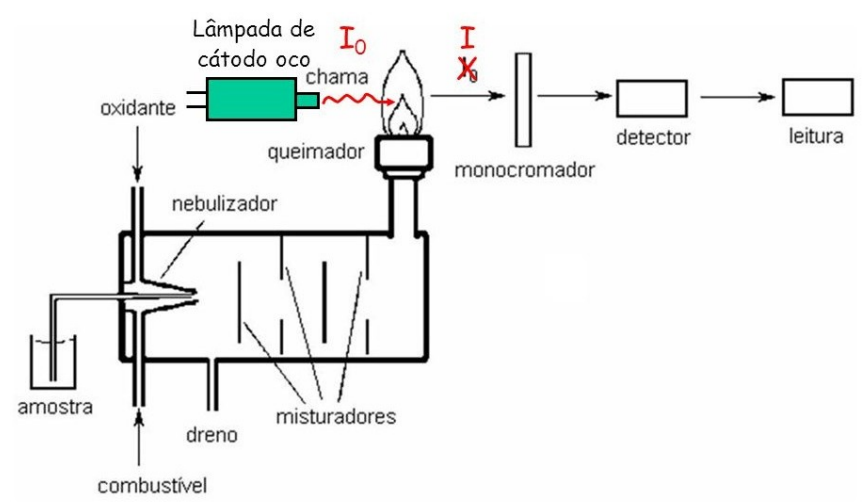

Figura 8: Esquema de funcionamento da absorção atômica. A luz emitida pela lâmpada de cátodo oco é dividida, os pulsos são recombinados após transpassarem os analitos vaporizados na chama. As linhas de emissão e absorção têm diferenças na largura dos picos, o sistema avalia a razão entre o log das intensidades, $\log \left(\frac{P_{0}}{P}\right)$.

Fonte: http://slideplayer.com.br/slide/1609688/

Descrevemos abaixo o método utilizado para a dosagem de metais divalentes e do ferro utilizando esta técnica. Nesse procedimento, a amostra é dividida em triplicata e são retirados $100 \mu \mathrm{l}$ de ferrofluido da amostra para cada béquer, que são levados ao aquecimento junto com $10 \mathrm{ml}$ de ácido clorídrico e $20 \mathrm{ml}$ de água destilada. 
Após a ebulição, são resfriados para, em seguida, serem transferidos para os balões volumétricos e então as amostras são levada para as medidas no absorção atômica. Os resultados obtidos serão apresentados na seção de resultados.

\subsection{Densidade de coloides magnéticos}

A densidade dos coloides magnéticos relaciona a razão entre a quantidade de matéria - nanopartículas e o dispersante - e o volume que ocupam. A relação entre densidade e concentração pode ser utilizada para a determinação do estado físico em que o nanocolóide magnético se encontra. Uma propriedade importante nestes materiais é a tensão superficial, que pode alterar o grau de adesão ligado às suas superfícies. No caso das nanopartículas magnéticas a densidade pode ser extraída a partir de medidas da densidade de fluidos magnéticos diluídos em função da fração volumétrica da nanopartícula.

Podemos ainda definir a densidade de uma partícula como o somatórios das massas molares das fases que a constituem considerando o modelo núcleo superfície explicado anteriormente, dividida pelos volumes molares correspondentes [14], ou seja:

$$
\rho_{\text {part }}=\frac{\sum_{1}^{n} X_{m}^{i} M_{m}^{i}}{\sum_{1}^{n} X_{m}^{i} V_{m}^{i}}
$$

$$
\rho_{\text {part }}=\frac{\left(1-3 X_{M}\right) M_{m}^{S}+2 X_{m} M_{m}^{C}}{\left(1-3 X_{m}\right) V_{M}^{S}+2 X_{m} V_{M}^{C}}
$$


Onde $X_{i}=1$ quando todas as frações iésimas forem consideradas na equação. As variáveis

$M_{s} \quad$ e $\quad M_{c}$ são as massas molares da superfície e do núcleo respectivamente, $V_{M}^{S}$ e $V_{M}^{C} \quad$ são os volumes molares da superfície e do núcleo respectivamente.

\subsection{Medida da densidade utilizando densímetro DMA 38 ANTON PAAR}

Ao longo da pesquisa, diversos processos foram realizados: síntese de nanopartículas magnéticas, suas caracterizações físico-químicas, avaliação de frações volumétricas em nanopartículas e as medidas de densidade das várias concentrações de ferrofluido.

A determinação da densidade é de suma importância para conhecer a natureza das interações que ocorrem em tais estados físicos. A tensão superficial [15], que está sujeita o material, tem forte influência sobre esse mecanismo [16]. O grau de suscetibilidade magnética, quando induzidas por campo magnético externo, também está sobre influência dos estados mais ou menos densos. O rendimento do ferrofluido é importante para o tipo de aplicação científico visado.

Para tanto, se faz necessário que se disponha de maneiras adequadas e precisas para medir a densidade dos mais diversos tipos de fluidos magnéticos compostos pelo grupo de metais divalentes, cada qual apresentando características físicas e químicas individuais [17].

Portanto, duas formas de medição são mais usualmente utilizadas, sendo elas: o densímetro e a balança de Arquimedes. Nas situações em que a amostra está diluída e possui densidade relativa próxima a da água, o uso do densímetro é adequado. Entretanto, quando a amostra apresenta viscosidade elevada, não é possível fazer essa media no densímetro, para tal utilizaremos outro método que será discutido em detalhe posteriormente.

\subsection{Princípio da medida}

Para a medição das fases diluídas, o densímetro é eficiente, pois sua utilização é simples e os valores das medidas são fornecidos após três minutos de medição. 
O densímetro utilizado foi o DMA 38 ANTON PAAR que, após calibrada a temperatura ambiente $\left(26,5^{\circ} \mathrm{C}\right)$ no período das medidas, forneceu os valores de densidade em $\mathrm{g} / \mathrm{cm}^{3}$ e gravidade específica.

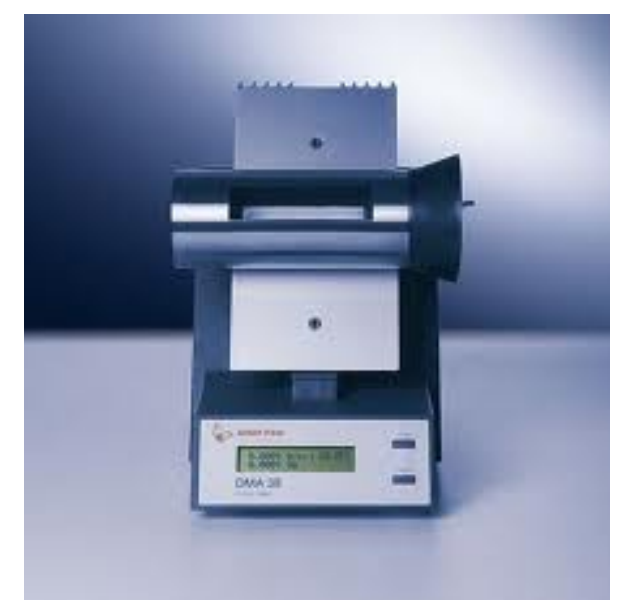

Figura 9: Aparelho DMA 38 ANTON PAAR, para medição de densidade e gravidade específica em função da temperatura ambiente.

Seu manuseio é de fácil operação, utilizando, para tal, seringas de $2,5 \mathrm{ml}$ e um pequeno béquer para descarte. O próprio aparelho possui um cano compressor que injeta ar em pulsos com alta pressão. A frequência com que o ar passa pelo tudo em formato de $U$ empurra para fora as pequenas gotas que ainda estejam presentes dentro no aparelho.

Em seguida, após a limpeza, observa-se o valor da densidade do ar a temperatura ambiente e, estando conforme esperado, pode iniciar-se novamente o processo de medição da amostra seguinte.

\subsection{Medidas da densidade das partículas utilizando balança de Arquimedes}

As medidas de densidade também podem ser realizadas por meio de outra técnica, a balança de Arquimedes, que foi fabricada no nosso laboratório para a elaboração deste trabalho. Como método alternativo ao densímetro, a balança de Arquimedes é eficiente, pois abrange a medida não somente de amostras diluídas estado líquido do ferrofluido - como também concentrados - estados sólido -, em que a viscosidade seja eleva ao ponto de não conseguir ser inserida no tudo em forma de $U$ do densímetro. Logo, o formato, a viscosidade e o volume reduzido da mesma 
não a impedem de ser postas em contato com o dodecano dentro dos copos utilizados na balança de precisão, dado o largo espaço disponível. Porém, o volume da amostra inserida dentro dos copos pode aumentar ou diminuir o erro relativo à precisão, visto que pequenos volumes estão sujeitos a maiores oscilações e não apresentam boa concordância com os valores do outro método se as frações medidas estiverem com variações muito próximos uns dos outros.

O dodecano é o material utilizado para se chegar à densidade relativa de qualquer tipo de amostra que seja medida, sua densidade é tabelada em função da temperatura, sendo seu uso apropriado para se chegar à densidade relativa dos materiais, já que seu volume não varia significativamente e nem ocorre evaporação em grande escala. A seguir, serão apresentados os princípios físicos envolvidos e o modo de operação usado nas medidas de densidade do ferrofluido por pesagem. Como dito anteriormente, a balança de Arquimedes apresenta uma alternativa para se chegar aos valores de densidade, utilizando matérias de difícil manipulação, devido à forma e estados físicos mais complexos. As informações sobre a amostra são obtidas através de quatro pesagens, nas quais duas medidas de massa são realizadas com a presença de ferrofluido e outras duas sem ele. As medidas sem o ferrofluido permitem a exclusão da densidade do próprio material utilizado para medição, deixando unicamente o volume injetado na balança para análise.

As quatro pesagens permitem subtrair a diferença entre ambos os casos suspensas e assentadas - que nos darão o valor da massa da amostra, que é referente ao resultado em gramas dado pela balança, segundo as equações apresentadas mais a frente. As outras duas medidas de massas são relacionadas com a densidade relativa do ferrofluido com base na densidade do dodecano. Em seguida, são realizados cálculos que resultam no volume deslocado. Tendo em vista que a densidade se relaciona a duas grandezas físicas - razão entre massa e volume -, as medidas obtidas por essa técnica alcançam até a quarta casa decimal abaixo do grama.

Portanto, pequenas quantidades - por volta de $1 \mathrm{ml}$ - são suficientes para se chegar à densidade de qualquer tipo de material. Sabe-se que todo material possui uma densidade que correspondem ao volume ocupado por uma quantidade de material no espaço, no sistema internacional de medidas. A grandeza física da massa é dada em $\mathrm{kg}$ e o volume é dado em $\mathrm{m}^{3}$. 
Portanto, a razão entre ambas as grandezas é dada em $\mathrm{kg} / \mathrm{m}^{3}$, como a água é o elemento mais abundante na superfície da Terra, por convenção, todas demais matérias são medidas com referência à densidade da mesma. A razão entre a massa/volume de qualquer material com a razão massa/volume da água implica na densidade relativa entre ambos.

Um litro de água equivale a um quilograma quando se encontra a temperatura a $4^{0} \mathrm{C}$ - $1,0 \mathrm{~g} / \mathrm{cm}^{3}$ - durante a medida. Entretanto, cada material possui uma organização atômica diferenciada, possuindo composição química (organização molecular) e física (massa dos nucleons dentro dos átomos) individual. Portanto, diferentes materiais ocupando mesmo volume possuem qualidades diferentes.

As medidas na balança são altamente sensíveis, as unidades adotadas são usualmente $\mathrm{g} / \mathrm{cm}^{3}$, ou em termos de volume $\mathrm{g} / \mathrm{ml}$ para facilitar as transformações de unidades.

Com a técnica da balança de Arquimedes, torna-se possível determinar tanto a massa quanto o volume de qualquer amostra, sem recorrer a balões ou cálculos complexos. O processo se dá com a utilização de material com densidade conhecida dodecano $0,7421 \mathrm{~g} / \mathrm{cm}^{3}$ - que é usado como fator comparativo, e as quatro pesagens sucessivas, sem e com amostra, resultam nos valore e densidade. A figura 10, a seguir, representa o modo de operação do sistema em questão.
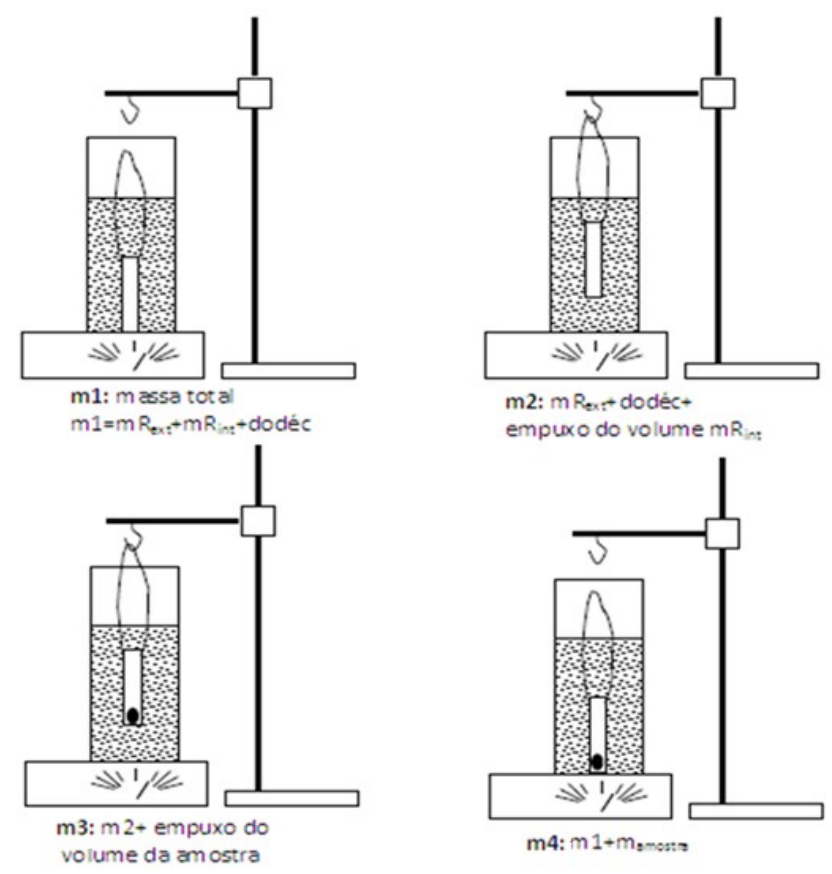
Figura 10: Princípio da medida de densidade utilizando a balança de Arquimedes, em que constam os materiais usados: Balança, copos de medida, dodecano e o anteparo.

Fonte: Coppola P.; Dissertação; 2010.

Os materiais utilizados pela balança de Arquimedes são: balança, Béquer, Dodecano $0,7421 \mathrm{~g} / \mathrm{cm}^{3}$, copo, anteparo, fio de tração e amostra analisada. Todas as medidas são realizadas a temperatura ambiente, devido à eficiência do dodecano como material inerte, com pouca dilatação térmica e difícil evaporação em tais condições.

Primeiramente, tara-se a massa de um pequeno béquer contendo $15 \mathrm{ml}$ de dodecano, em seguida um pequeno copo com volume bem inferior ao béquer é imerso no fluido e pesado. Tais medidas dão o peso e, consequentemente, o volume do pequeno copo que receberá a amostra. Dessa forma, o copo desloca o volume original quando suspenso e preso pelo apoio, conforme observado na figura 10.

A massa do béquer, contendo o fluido de dodecano com densidade conhecida, é desconsiderada. Contudo, o copo porta amostra é pesado assentado dentro do béquer/dodecano sem ferrofluido e é representada por $m_{1}$. Já a massa medida do copo suspenso dentro do béquer/dodecano sem ferro fluido corresponde a $m_{2}$. As massas $m_{3}$ e $m_{4}$ são, a princípio, suspensas e assentadas contendo ferrofluido. Sendo assim, a diferença entre as massas $m_{4}-m_{1}$ implica na massa do líquido deslocado. Por conseguinte, a razão entre a diferença de $\begin{array}{lllll}m_{3} & \text { e } & m_{2} & \text { e a densidade }\end{array}$ relativa do dodecano $\Delta \mathrm{Vol}=\left(m_{3}-m_{2}\right) / \rho_{\text {dodec }}$ fornece o volume deslocado no sistema.

O processo da pesagem com a amostra, portanto, segue os seguintes passos: quatro pesagens sucessivas, em que duas fornecem o valor da massa com o copo suspenso, e as duas seguintes com o copo assentado ao fundo do béquer que resulta no valor do volume deslocado.

Como inicialmente, o procedimento só continha o copo porta amostra, essa massa pode ser extraída quando novamente se fazem o mesmo ciclo de pesagens agora com as amostras de ferrofluido. Reorganizando os fatores e chegamos ao valor da densidade, como podemos verificar na equação 15 :

$$
M_{\text {amostra }}=m_{4}-m_{1}
$$




$$
V_{\text {amostra }}=\frac{\left(m_{3}-m_{2}\right)}{\rho_{\text {dodec }}}
$$

$$
\begin{aligned}
& m \\
& \frac{\left(\dot{i} \dot{4} 4-m_{1}\right)}{\left(m_{3}-m_{2}\right)} \frac{\rho_{\text {dodec }}}{\rho_{\text {água }}} \\
& \rho_{F F}=i
\end{aligned}
$$

Onde, $m_{1}$ é pesagem imersa sem ferrofluido; $m_{2}$, pesagem suspensa sem ferrofluido; $m_{3}$, pesagem suspensa com ferrofluido e; $m_{4}$, pesagem imersa com ferrofluido.

\section{RESULTADOS OBTIDOS}

Nesta seção, apresentamos a análise e discussão dos resultados obtidos para as nanopartículas e nanocolóides sintetizados no presente trabalho. Primeiramente, apresentamos os resultados relacionados à estrutura cristalina e ao tamanho médio dos materiais investigados aqui, utilizando a técnica de difração de raios x. Em seguida, apresentamos o estudo da morfologia e da dispersão em tamanhos destes materiais analisados, a partir da técnica de microscopia eletrônica de transmissão. Os resultados da composição química das amostras são apresentados utilizando a técnica de espectrometria de absorção atômica. Por fim, apresentamos os resultados das medidas de densidade para o nanocolóide em diferentes frações volumétricas em nanopartículas, utilizando um densímetro e uma balança de Arquimedes. Vale ressaltar que todas essas técnicas foram apresentadas na seção anterior.

\subsection{Difração de raios x e Microscopia Eletrônica de Transmissão}

Conforme discutimos anteriormente, a técnica de difração de raios x é uma das mais poderosas técnicas para investigação da estrutura e tamanho de materiais 
cristalinos nanoestruturados. O padrão de difração de raios $\mathrm{x}$, para as nanopartículas sintetizadas neste trabalho, foi obtido utilizando um difratômetro da Bruker, modelo D8 Focus, instalado no Instituto de Química da UnB com radiação $\mathrm{CuKa}$ a $40 k V$ e $30 \mathrm{~mA}$, com velocidade de $0,1^{\circ} \mathrm{min}-1$, passo de $0,05^{\circ}$ e comprimento de onda $\lambda=0,15406 \mathrm{~nm}$. O método do pó foi utilizado para a realização da medida, ou seja, as amostras foram secadas em uma estufa à $120^{\circ} \mathrm{C}$, logo após a obtenção das nanopartículas ( $3^{\circ}$ etapa de síntese). As distâncias interplanares foram calculadas utilizando a lei de, apresentada na seção 1 (equação 9), e seus valores foram comparados com aqueles das tabelas do ICDD (arquivo 00-022-1086), permitindo a indexação dos picos característicos associados às famílias de plano $(h k l)$ da estrutura cristalina [14]. No caso das ferritas do tipo espinélio, que possuem simetria cúbica, podemos relacionar a distância interplanar com os índices de Milller, utilizando a expressão, $\quad d_{h k l}=\frac{a}{\sqrt{h^{2}+k^{2}+l^{2}}}$. Esta equação nos permite, após a indexação do difratograma, determinar o parâmetro de malha cúbica. A figura 11 mostra o difratograma da amostra estudada nessa dissertação. A indexação dos picos nos permite determinar o parâmetro de malha $\langle a\rangle_{I C D D}=0,8347 \mathrm{~nm}$ e confirmar a estrutura espinélio [18]. O valor de $\langle a\rangle$ está em bom acordo com o valor tabelado $\langle a\rangle_{\text {ICDD }}=0,8391 \mathrm{~nm}$, conforme descrito na tabela 1 .

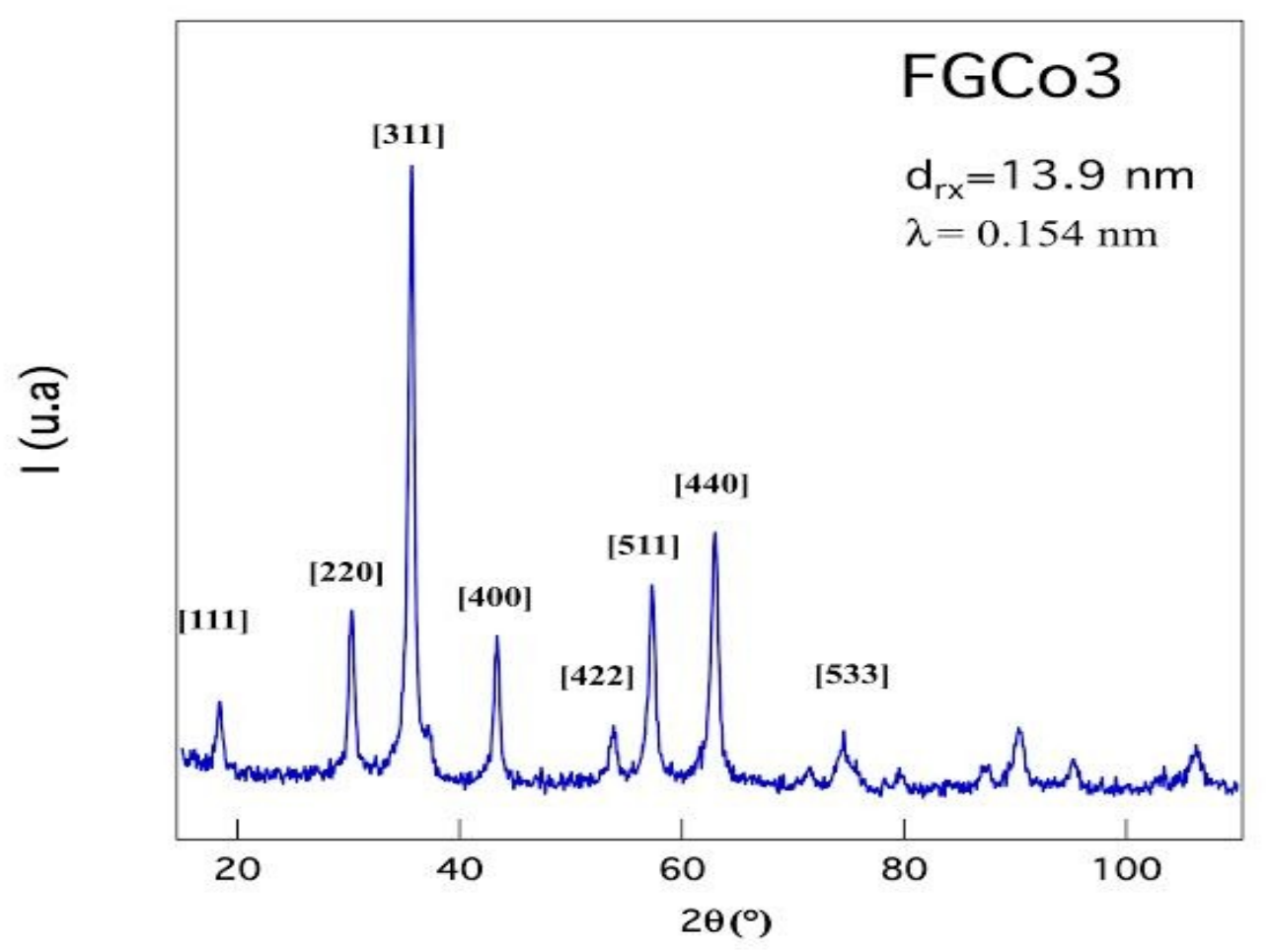


Figura 11: Difratogramas de raios x obtidos para amostras constituídas de ferrita de cobalto. A intensidade do feixe difratado é representada em função do ângulo, 2 $\theta$, em graus $\lambda=0,15406 \mathrm{~nm}$.

Para a determinação do diâmetro médio, foi utilizado o formalismo de Scherrer [19] $d_{h k l}=\frac{k \lambda}{\beta \cos \theta}$, onde $\beta$ é a largura a meia altura do pico de maior intensidade, $k$ é uma constante de proporcionalidade que está associada à forma da nanopartícula. Neste caso, como as partículas utilizadas na elaboração de fluidos magnéticos têm, tipicamente, formato esférico, considera-se o valor $k=0,9$ na aplicação dos cálculos $[20,21]$. A partir do valor de $\beta$, encontramos um diâmetro médio $d_{r x}=13,9 \mathrm{~nm}$. A técnica de difração de raios $\mathrm{x}$ fornece informações sobre a estrutura cristalina dos materiais, no entanto, não nos dá informação a cerca da morfologia das nanopartículas [22], para isso utilizamos a técnica da microscopia eletrônica de transmissão [23]. Ainda, a partir dessa técnica, é possível estimar a dispersão em tamanhos das nanopartículas e determinar seu diâmetro médio [24], $\mathrm{d}_{0}$. Obtemos as imagens de MET utilizando um microscópio eletrônico de transmissão JEL JEM-100 CX II e para o caso das imagens, em alta resolução, foi utilizado um microscópio eletrônico JEOL JEM-2010. Essas medidas foram feitas na Université Pierre et Marie Curie, em Paris, na França.

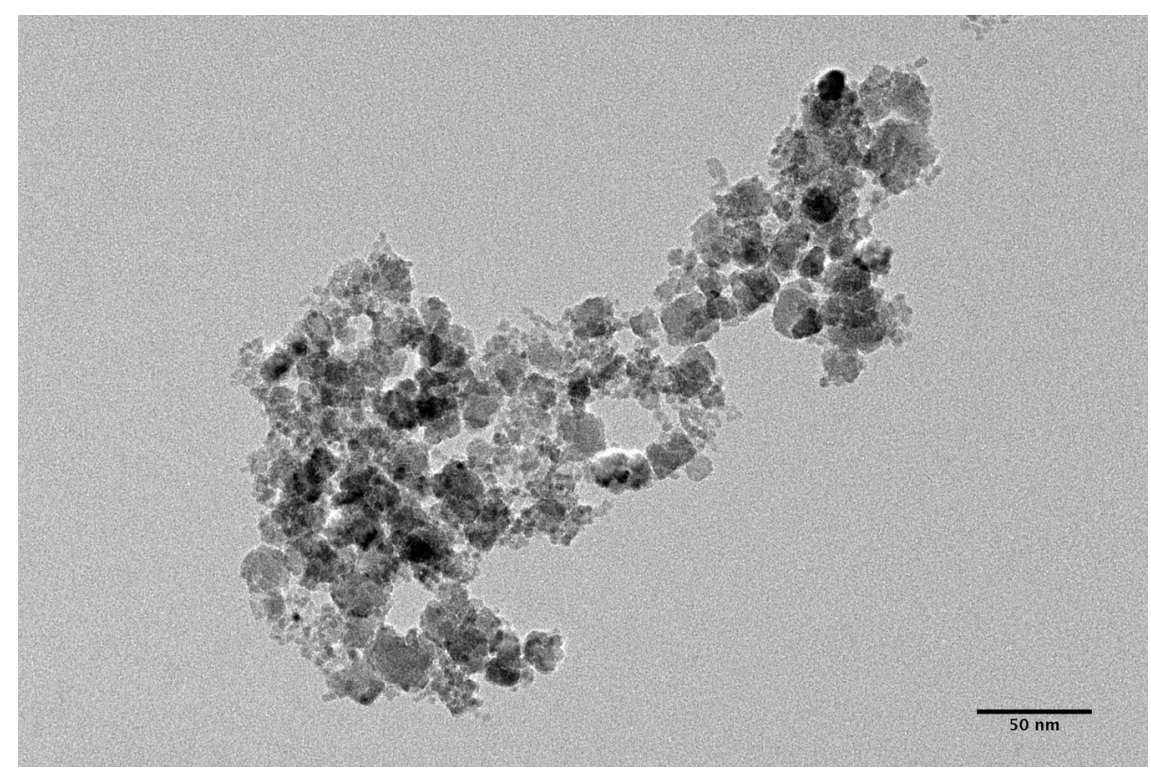

Figura 12: Imagem típica de micrografia para a amostra FG3 
A figura 12 mostra uma das imagens típicas de MET das nanopartículas sintetizadas neste trabalho. Podemos verificar que elas são aproximadamente esféricas e que apresentam uma dispersão nos tamanhos. Para estimar essa polidispersão em tamanhos, foram feitas contagens de aproximadamente 120 nanopartículas, não envolvidas em aglomerados, em diferentes imagens e analisadas manualmente utilizando o software de domínio público image $J$. A partir dessa contagem, um histograma de tamanhos foi obtido, conforme exemplificado na figura 13, a seguir [25].

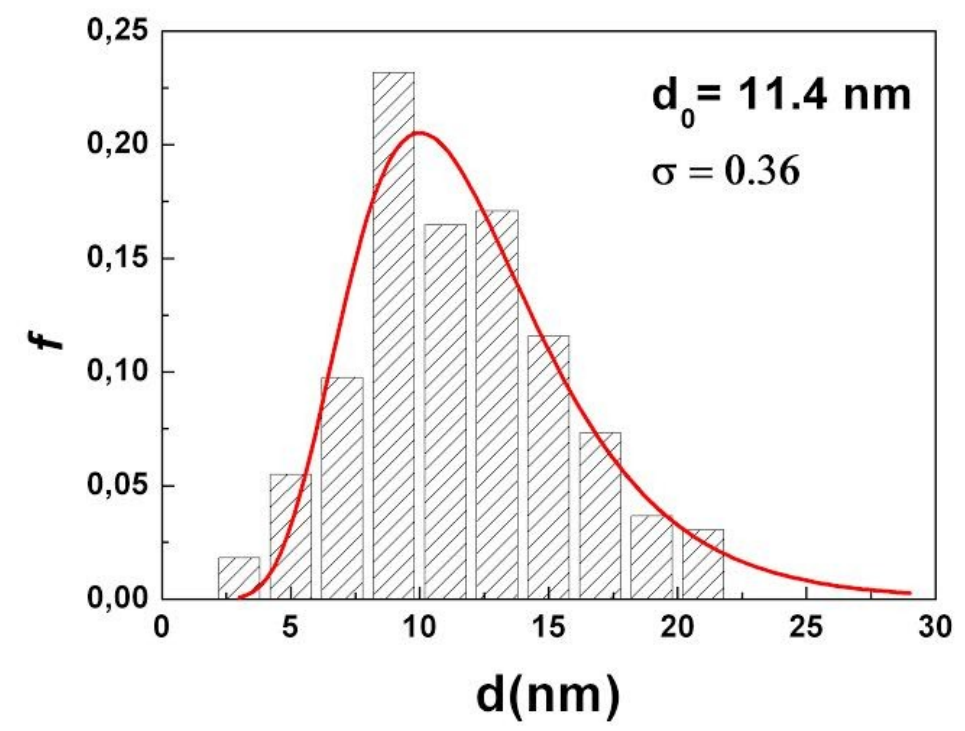

Figura 13: Histograma normalizado da distribuição de tamanhos das nanopartículas para a amostra FG3.

O melhor ajuste do histograma é obtido utilizando uma função do tipo lognormal dada pela expressão [25]:

$$
P(d)=\frac{1}{\sqrt{2 \pi s d}} \exp \left[\frac{-1}{2 s^{2}}\left(\ln \frac{d}{d_{0}}\right)^{2}\right]
$$

Sendo $\quad d_{0} \quad$ o valor do diâmetro característico, $\quad\left(\ln d_{0}=\langle\operatorname{lnd}\rangle\right), \quad s \quad$ refere-se à largura relacionada às variações de diâmetros do sistema polidisperso.

Entretanto, para se analisar a estabilidade coloidal, deve-se considerar um tamanho médio das nanopartículas, pois a estabilidade física depende de um limite de 
diâmetro [27], onde o movimento browniano consegue superar a força gravitacional $\lim i=\left(\frac{6 K_{b} T}{\pi \Delta \rho g h}\right)^{1 / 3}$, para isso usa-se a distribuição de diâmetro mais provável, $d_{m p}=d_{0} \exp \left(-s^{2}\right)$, onde $d_{m p}$ é o diâmetro mais provável [28]. Por outro lado, considerando uma média global desta distribuição histográfica a função toma forma: $\langle\boldsymbol{d}\rangle=d_{0} \exp \left(\frac{-\sigma^{2}}{2}\right)$, onde $\langle\boldsymbol{d}\rangle \quad$ é o diâmetro médio das nanopartículas. Podemos, ainda, relacionar o diâmetro característico $d_{0}$ à polidispersão $\sigma$, obtidos a partir de MET com o diâmetro cristalino $d_{r x}$, que é obtido a partir de difração de raios $\mathrm{x}$, utilizando a expressão $d_{\text {calc }}^{r x}=d_{0} \exp \left(2,5 \sigma^{2}\right)$. A tabela 1 reúne as características estruturais determinadas por difração de raios $\mathrm{x}$ e as características morfológicas das nanopartículas obtidas a partir de MET. Verificamos que os tamanhos de raios $\mathrm{x}$ e de microscopia estão em bom acordo, e que o tamanho associado à partícula, mesmo levando-se em conta a polidispersão, é inferior ao tamanho limite determinado por de cálculos hidrodinâmicos, a fim de garantir a estabilidade de nanocoloides em meio aquoso [24].

Tabela 1: $\mathrm{d}_{\mathrm{rx}}$ - diâmetro cristalino determinado a partir da fórmula de Scherrer, $\langle\boldsymbol{a}\rangle$ : é o parâmetro de malha, $d_{0}$ : diâmetro característico, $\sigma$ : índice de polidispersão associado a uma distribuição do tipo log-normal e $d_{\text {calc }}^{r x}$ : diâmetro calculado a partir da relação, $\quad d_{\text {calc }}^{r x}=d_{0} \exp \left(2,5 \sigma^{2}\right),\langle\boldsymbol{d}\rangle$ : diâmetro médio das nanopartículas, $d_{m p}$ : diâmetro mais provável.

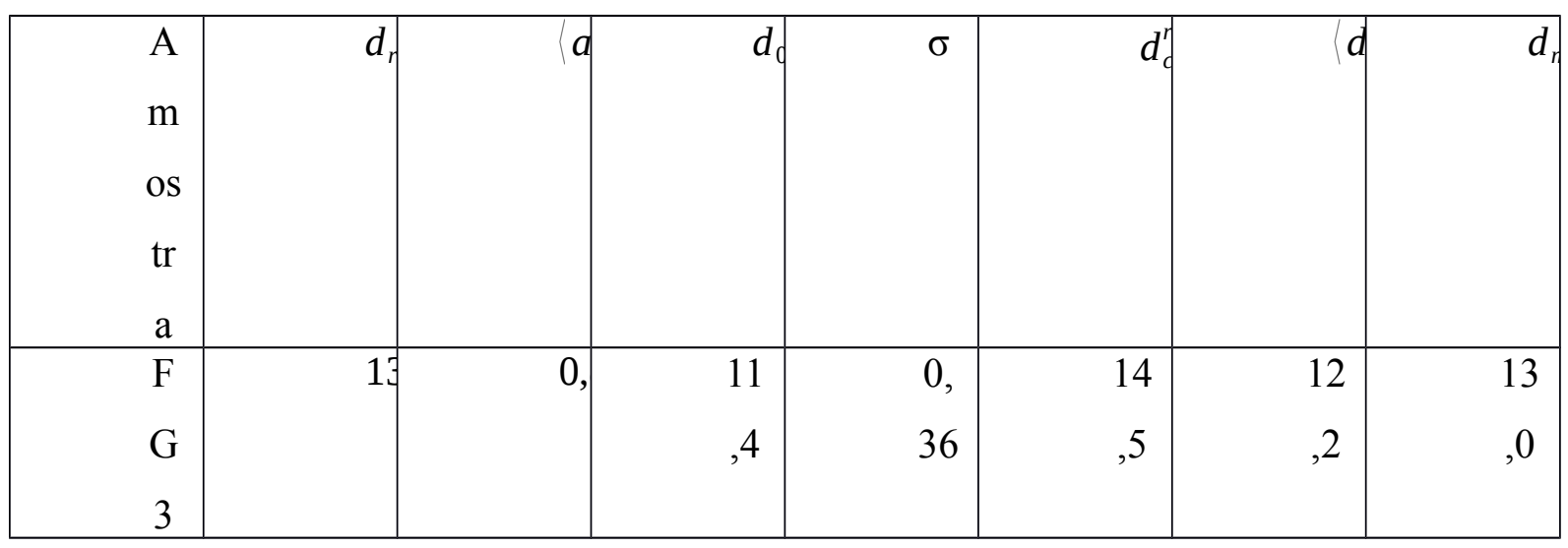

A figura 14 mostra uma imagem típica em alta resolução de uma nanopartícula isolada para a amostra FG3. 


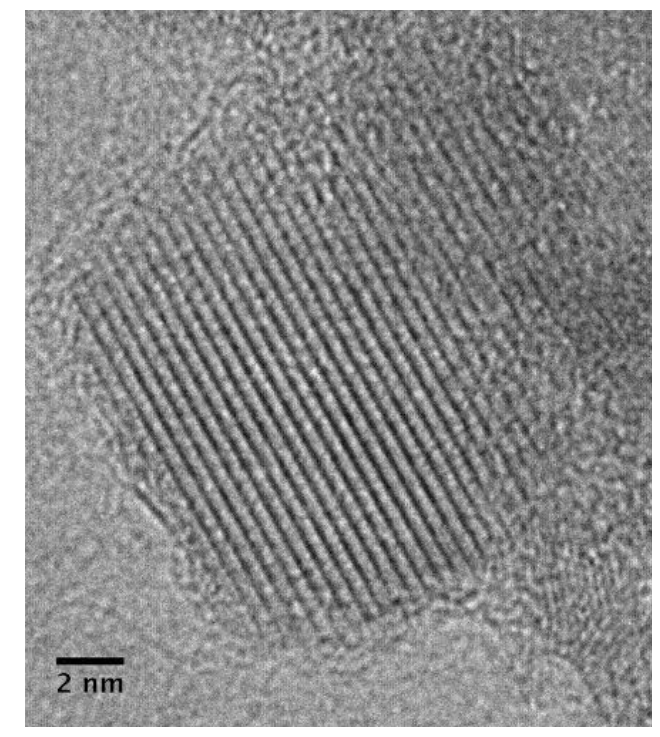

Figura 14: Imagem em alta resolução de uma partícula única para a amostra FG3.

Essa imagem apresenta um conjunto de planos reticulares. A distância interplanar é da ordem de $0,47 \mathrm{~nm}$, correspondente aos índices de Miller (l 111$)$, em bom acordo com o arquivo de dados 00-022-1086 (ICDD), cujo valor é de aproximadamente $0,48 \mathrm{~nm}$. Essa distância foi determinada por meio do software de domínio público image $J$, utilizando a ferramenta da transformada de Fourier disponível.

\subsection{Composição Química da amostra FG3}

Conforme explicado anteriormente, na seção 2.2, para evitar a dissolução das partículas em meio aquoso ácido, após a etapa 1 de síntese, as nanopartículas são submetidas a um processo empírico de tratamento hidrotérmico em solução de nitrato férrico. Esse processo tem como consequência um enriquecimento em ferro na composição das nanopartículas, o que é interpretado através da formação de um modelo de composição química núcleo-superfície [9]. Mais especificamente, para as nanopartículas estudadas neste trabalho, temos um núcleo formado por uma ferrita de cobalto $\left(\mathrm{CoFe}_{2} \mathrm{O}_{4}\right)$ recoberta por uma camada superficial de maghemita ( $\left.\gamma-\mathrm{Fe}_{2} \mathrm{O}_{3}\right)$.

Os formalismos matemáticos relacionados ao modelo núcleo-superfície de composição química foram apresentados na seção 2.4. Neste contexto, analisamos aqui 
os resultados obtidos, para o nanocoloide FG3, utilizando a técnica de dicromatometria e espectrometria de absorção atômica. Para o caso da ferrita de cobalto, estudada aqui, a fração volumétrica de nanopartículas magnéticas é dada por $\phi_{p}=\phi_{c}+\phi_{s}$, onde

$$
\begin{gathered}
2+i \\
C o \\
i \\
\phi_{c}=i
\end{gathered}
$$

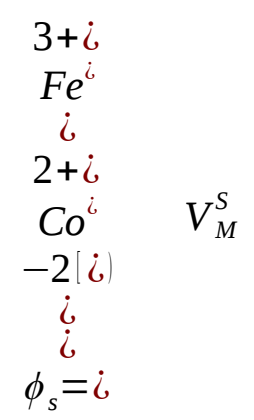

(18)

$\phi_{c}$ é a fração volumétrica do núcleo, proporcional à concentração de cobalto $\mathrm{Co}^{2+}$; e $\phi_{S}$, a fração volumétrica da camada superficial, proporcional à concentração de ferro fora do núcleo de ferrita [9]. O volume molar do material do núcleo ( $V_{M}^{C}=43,53 \cdot 10^{-3} \mathrm{~L} / \mathrm{mol}$ ) é o volume molar da ferrita de cobalto. Para a camada superficial, considera-se o volume molar $\left(V_{M}^{S}=31,47.10^{-3} \mathrm{~L} / \mathrm{mol} \dot{i}\right.$ da maghemita [30], já que este é o único óxido de ferro de estrutura espinélio, compatível com as nossas análises de raios $\mathrm{X}$. A tabela reúne um conjunto de dados obtidos por espectrometria de absorção atômica. Primeiramente, determinamos a concentrações molares em mol/l de metais divalente $\mathrm{Co}^{2+}$ e do $\mathrm{Fe}^{3+}$. A fração molar em metal divalente pode ser obtida a partir dessas concentrações obtidas e utilizando a expressão: 


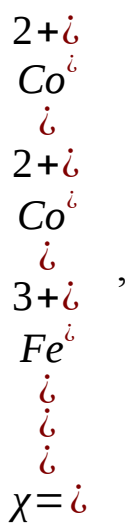

O valor encontrado para o nanocoloide estudado foi de 0,27 , diferentemente do valor ideal $(0,33)$, esperado para uma ferrita de estequiometria ideal, o que corrobora a alteração na composição das partículas, após o tratamento em nitrato férrico.

Tabela 2: $\quad d_{r x}$ - diâmetro cristalino determinado à partir da fórmula de Scherrer, $\begin{array}{ccc}2+i & \begin{array}{c}3+i \\ C o^{i}\end{array} & \text { e } \\ i & F^{i} & i\end{array}$ : são as concentrações molares de cobalto e ferro respectivamente, $\chi_{m}$ : é a fração molar em metal divalente, fração em volume da ferrita de cobalto no núcleo, fração em volume da maghemita na superfície, $e$ é a espessura da camada de maghemita, $e / r$ é a razão entre a a espessura de maghemita e o raio da nanopratícula.

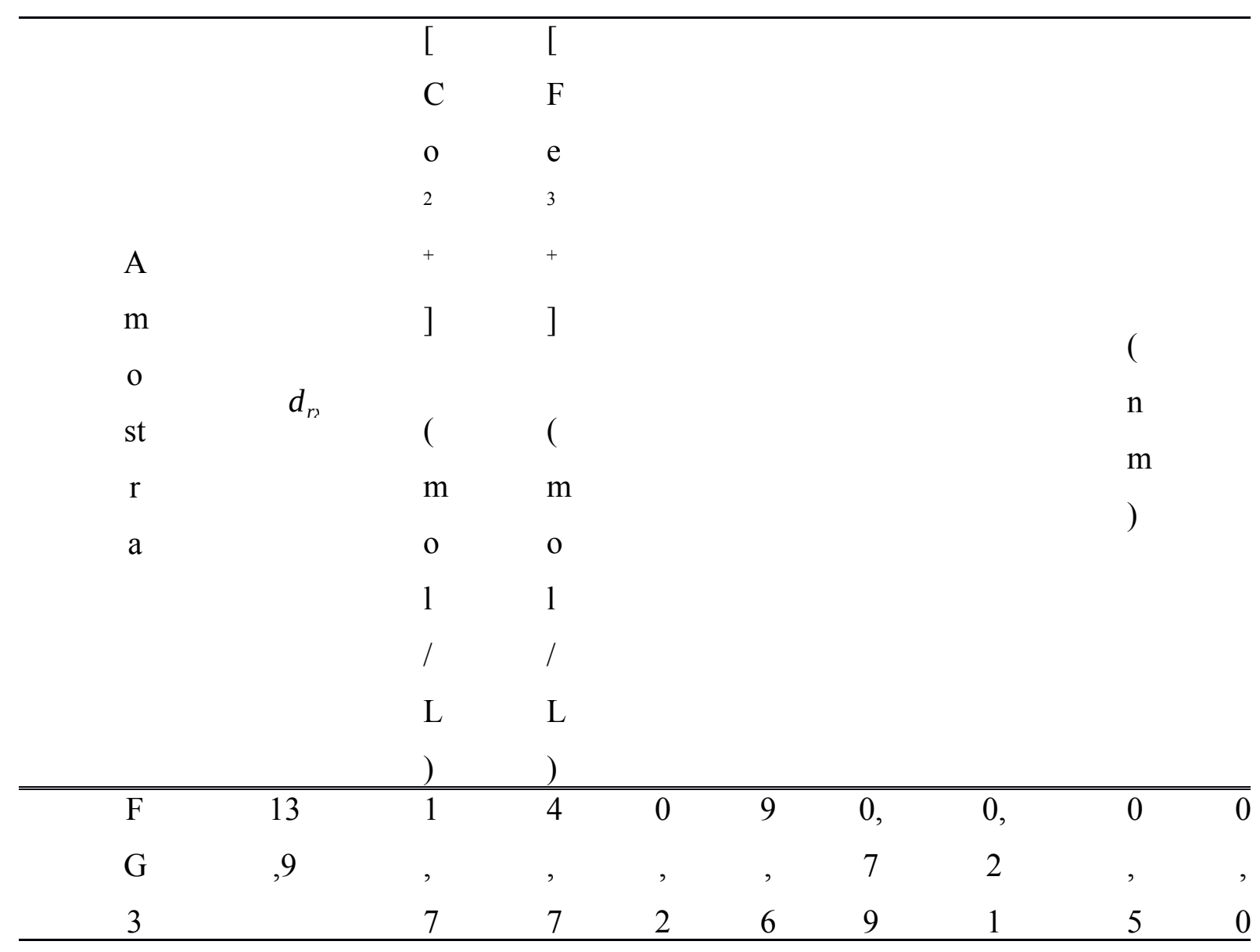


A partir das dosagens químicas dos íons metálicos, podemos determinar a fração volumétrica das nanopartículas ( $\phi_{P} \dot{i}$. Utilizando a equação 20 abaixo [31], é possível determinar o valor da espessura da camada superficial enriquecida em ferro, onde $\mathrm{n}_{\text {core }}$ e $\mathrm{n}_{\text {shell }}$ são os números de íons metálicos nas estruturas do núcleo e da superfície, $\mathrm{d}_{\mathrm{rx}}$ é o diâmetro médio, determinado por difração de raios $\mathrm{x}$.

$$
e=\frac{d_{r x}}{2}\left\{1-\left[\left(\frac{1}{\frac{\phi_{c}}{\phi_{p}}}-1\right) \frac{n_{\text {Core }}}{n_{\text {Shell }}}+1\right]^{\frac{-1}{3}}\right\}
$$

$\mathrm{O}$ valor de $\phi_{s} / \phi_{P}$ permite avaliar a fração de superfície presente nas nanoparticulas estudadas. Neste caso, verificamos uma quantidade de $20 \%$ da partícula que está relacionada à superfície [32].

\subsection{Medidas de densidade}

Como podemos verificar, o parâmetro experimental a ser determinado no cálculo da fração volumétrica em partículas, é a concentração em mol/L dos metais. Esta concentração é obtida a partir de técnicas analíticas de dosagem titrimétrica e por espectrometria de absorção atômica. Contudo, o bom resultado dessas determinações depende da acurácia nas tomadas de alíquotas da amostra.

$\mathrm{O}$ ato de medir as quantidades exatas de volumes ou massas, apesar de ser uma atividade simples, pode ser fonte de erros determinados e erros indeterminados. Neste caso, os erros determinados são associados ao uso de equipamentos descalibrados ou erro de habilidade do experimentador. Estes erros são grosseiros e devem ser eliminados do processo de obtenção de dados. Entretanto, os erros indeterminados, no nosso caso, podem originar-se das dificuldades intrínsecas das propriedades dos sistemas coloidais, que não são soluções verdadeiras. De fato, aspectos como força iônica do meio, transição de fase tixotrópica e, sobretudo, o aumento da viscosidade do 
material coloidal com o aumento da concentração dificultam ou mesmo impedem a tomada de volumes usando pipetas ou outros equipamentos analíticos. Neste contexto, abordamos este problema, como foco do presente trabalho, visando utilizar as medidas de densidade dos nanocolóides como ferramenta na determinação exata e precisa de volumes.

Neste caso, utilizamos, aqui, a associação das dosagens químicas com medidas da densidade dos fluidos magnéticos para determinação da fração volumétrica. $\mathrm{Na}$ figura abaixo temos o comportamento esquemático da densidade do fluido $\rho_{F F}$, onde $\rho_{s}$ é a densidade do sólido e $\rho_{\mathrm{H}_{2} \mathrm{O}}$ a densidade do solvente [32].

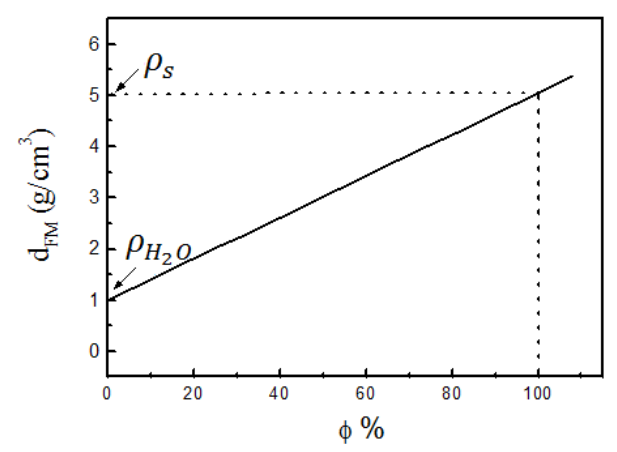

Figura 15: Densidade do fluido magnético em função da fração volumétrica em material $\phi$.

Podemos, então, escrever o $\phi$ de uma amostra de fluido magnético em função destes parâmetros:

$$
\phi_{p}()=\frac{\rho_{F F}-\rho_{H_{2} O}}{\rho_{S}-\rho_{H_{2} O}}
$$

Rearranjando a expressão acima, temos:

$$
\rho_{F F}=\rho_{S} \phi_{p}+\rho_{H_{2} O}\left(1-\phi_{p}\right)
$$

Desse modo, podemos relacionar a densidade de medida do nanocolóide ao $\phi_{p} \quad$ e a densidade da nanopartícula. Assim, utilizando a amostra FG3 e a água, foram 
realizadas medidas de densidade em densímetro digital e usando a balança de Arquimedes. $\mathrm{O}$ valor encontrado para a água pura tipo II, produzida por um purificador Elga (modelo LA611), foi a temperatura de $26,5{ }^{\circ} \mathrm{C}$ foi de $0,994 \mathrm{~g} / \mathrm{cm}^{3}$. As medidas foram realizadas para várias diluições de $0,007 \%$ a 9,6\% (em regime diluído), obtendo a dependência experimental da $\rho_{F F}$ com o $\phi_{p}$. As amostras foram utilizadas em uma condição de diluição que garantiu a viscosidade do fluido associada a um comportamento semelhante a um líquido newtoniano. Assim, apresentamos abaixo a curva de variação da densidade do ferrofluido em função do $\phi_{p}$, obtida utilizando o densímetro digital.

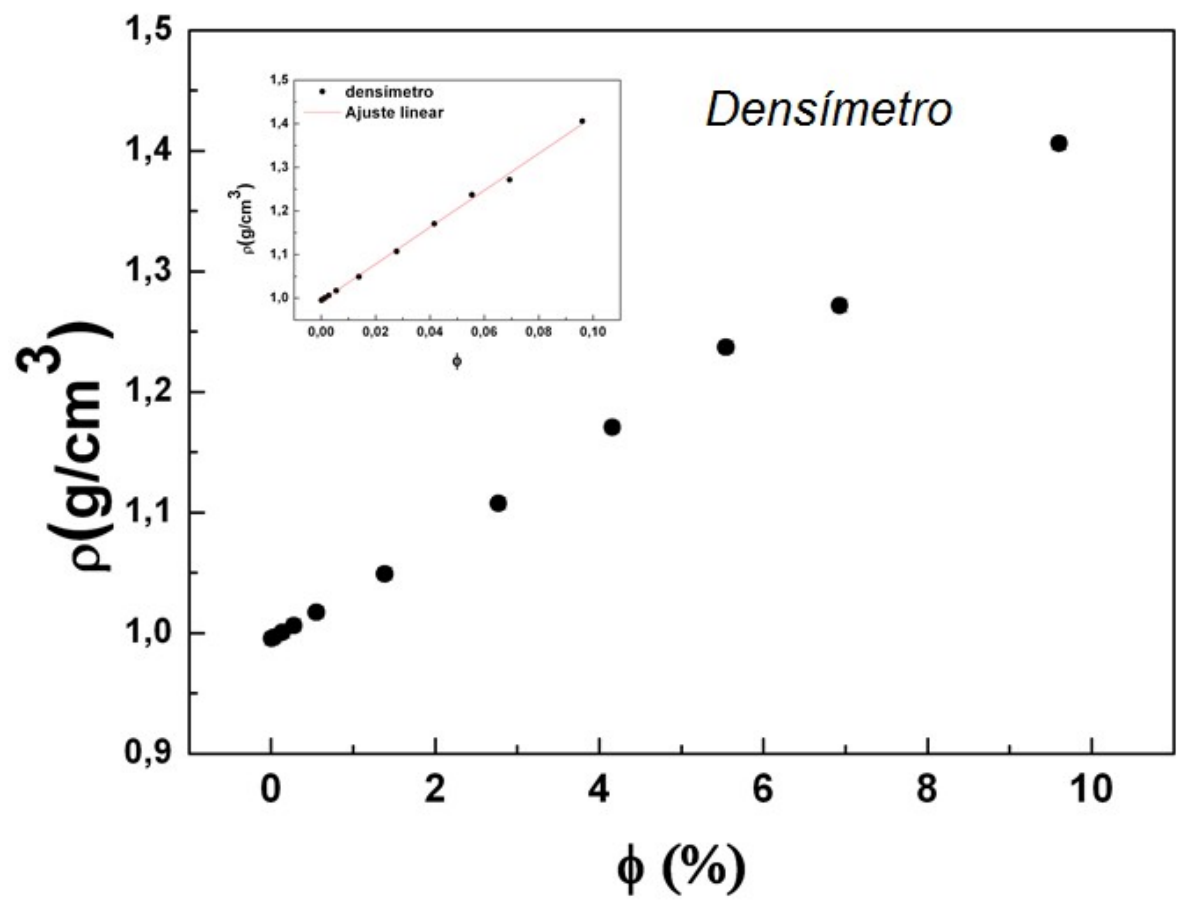

Figura 16: Densidade em função da fração volumétrica ( $\phi_{p}$ ) medida no densímetro. O detalhe mostra o ajuste dos dados experimentais com a expressão $\rho_{F F}=\rho_{S} \phi_{p}+\rho_{H_{2} O}\left(1-\phi_{p}\right)$.

Deste modo, apresentamos no detalhe o ajuste dos dados experimentais com a equação 22, onde foi possível determinar a densidade das nanopartículas Core/Shell, igual a 5,22 $\mathrm{g} / \mathrm{cm}^{3}$. Este valor é comparado, na tabela abaixo, com os valores calculados a partir da equação 12 e da ponderação de cada fase pela sua fração volumétrica, da seguinte maneira $\rho_{S}=\left(\frac{\phi_{S}}{\phi_{P}}\right) \rho_{\text {Shell }}+\left(\frac{\phi_{S}}{\phi_{P}}\right) \rho_{\text {Core }}$. Ainda, a tabela abaixo, coleta os valores da densidade da ferrita de cobalto e da maghemita. 
Tabela 3: $\quad \rho_{Y-\mathrm{Fe}_{2} \mathrm{O}_{3}}, \quad \rho_{\mathrm{COFe}_{2} \mathrm{O}_{4}}$ - são as densidades da maghemita e da ferrita de cobalto do tipo bulk respectivamente retiradas de [32], $\quad \rho_{\text {ajuste }}:$ a densidade da partícula retirada da equação $22, \quad \rho_{\text {Calc }} \quad:$ densidade calculada a partir da equação $12, \quad \rho_{\text {Calc1 }}$ : densidade calculada a partir da equação $\rho_{S}=\left(\frac{\phi_{S}}{\phi_{P}}\right) \rho_{\text {Shell }}+\left(\frac{\phi_{S}}{\phi_{P}}\right) \rho_{\text {Core }}$

\begin{tabular}{|c|c|c|c|c|}
\hline $\begin{array}{c}\rho_{\mathrm{Y}-\mathrm{Fe}_{2} \mathrm{O}_{3}} \\
\left(\mathrm{~g} / \mathrm{cm}^{3}\right)\end{array}$ & $\begin{array}{c}\rho_{\mathrm{CoFe}_{2} \mathrm{O}_{4}} \\
\left(\mathrm{~g} / \mathrm{cm}^{3}\right)\end{array}$ & $\begin{array}{c}\rho_{\text {ajuste }} \\
\left.\mathrm{g} / \mathrm{cm}^{3}\right)\end{array}$ & $\begin{array}{c}\rho_{\text {Calc }} \\
\left.\mathrm{g} / \mathrm{cm}^{3}\right)\end{array}$ & $\begin{array}{c}\rho_{\text {Calc1 }} \\
\left.\mathrm{g} / \mathrm{cm}^{3}\right)\end{array}$ \\
\hline 4,9 & 5,29 & 5,22 & 5,33 & 5,21 \\
\hline
\end{tabular}

O bom acordo entre os valores determinados teoricamente e o resultado do ajuste da curva de densidade evidencia a robustez da determinação da densidade e qualifica esta medida para a determinação acurada do volume das alíquotas a serem prelevadas. Ainda, a possibilidade de construção de curvas mestre para amostras que são utilizadas, seguidas vezes, pode facilitar a determinação do $\phi()$ e reduzir o gasto com reagentes e gases para absorção atômica, uma vez que a medida de densidade é uma técnica rápida e não destrutiva.

Entretanto, para amostras em elevadas concentrações, cuja viscosidade acarreta em um comportamento que diverge do liquido newtoniano a determinação de volumes e, por consequência, das concentrações molares, fica prejudicada. Para estas amostras, propusemos a utilização da montagem de uma balança de Arquimedes, descrita na seção 3.8, para determinar a densidade destes sistemas altamente viscosos.

Inicialmente, realizamos um teste para o caso da água tipo II, em que dez medidas, à temperatura de $27{ }^{\circ} \mathrm{C}$, foram coletadas, usando os dois métodos de medida de densidade. $\mathrm{Na}$ tabela abaixo, são reunidos os valores encontrados para as médias, o desvio padrão e os erros percentuais. Podemos destacar que os valores determinados por nós, usando o sistema denominado balança de Arquimedes possui um erro percentual associado à precisão entre os valores de 2,5\%. Ainda, se considerarmos o valor determinado, a mesma temperatura, utilizando o densímetro digital de bancada como o valor exato, verifica-se uma divergência de 3\%. Essa divergência pode ser entendida como o erro sistemático característico da montagem experimental, uma vez que se trata de um conjunto montado "com nossas mãos". Portanto, em todos os 
resultados obtidos, usando a balança de Arquimedes, consideramos o erro total como a soma do erro aleatório (erro percentual) mais o erro sistemático do conjunto montado.

Tabela 4: Densidades da água

$\rho_{\mathrm{H}_{2} \mathrm{O}}$ e seus respectivos erros obtidos à partir dos diferentes métodos, balança de Arquimedes e Densímetro.

\begin{tabular}{|c|c|c|}
\hline & Arquimedes & DM38 \\
\hline $\boldsymbol{\rho}\left(\mathrm{H}_{2} \mathrm{O}\right) \mathrm{g} / \mathrm{cm}^{3}$ & 0,9671 & 0,9973 \\
\hline Desvio Padrão & 0,0244 & 0,0000 \\
& & 7 \\
\hline $\begin{array}{c}\text { Erro } \\
\text { Percentual }\end{array}$ & 2,52 & 0,01 \\
\hline
\end{tabular}

Neste contexto, os mesmos fluidos magnéticos em concentrações entre $0,007 \%$ a $9,6 \%$ tiveram, então, suas densidades medidas, utilizando a balança de Arquimedes. Os valores obtidos, bem como o erro associado, são apresentados na figura abaixo.

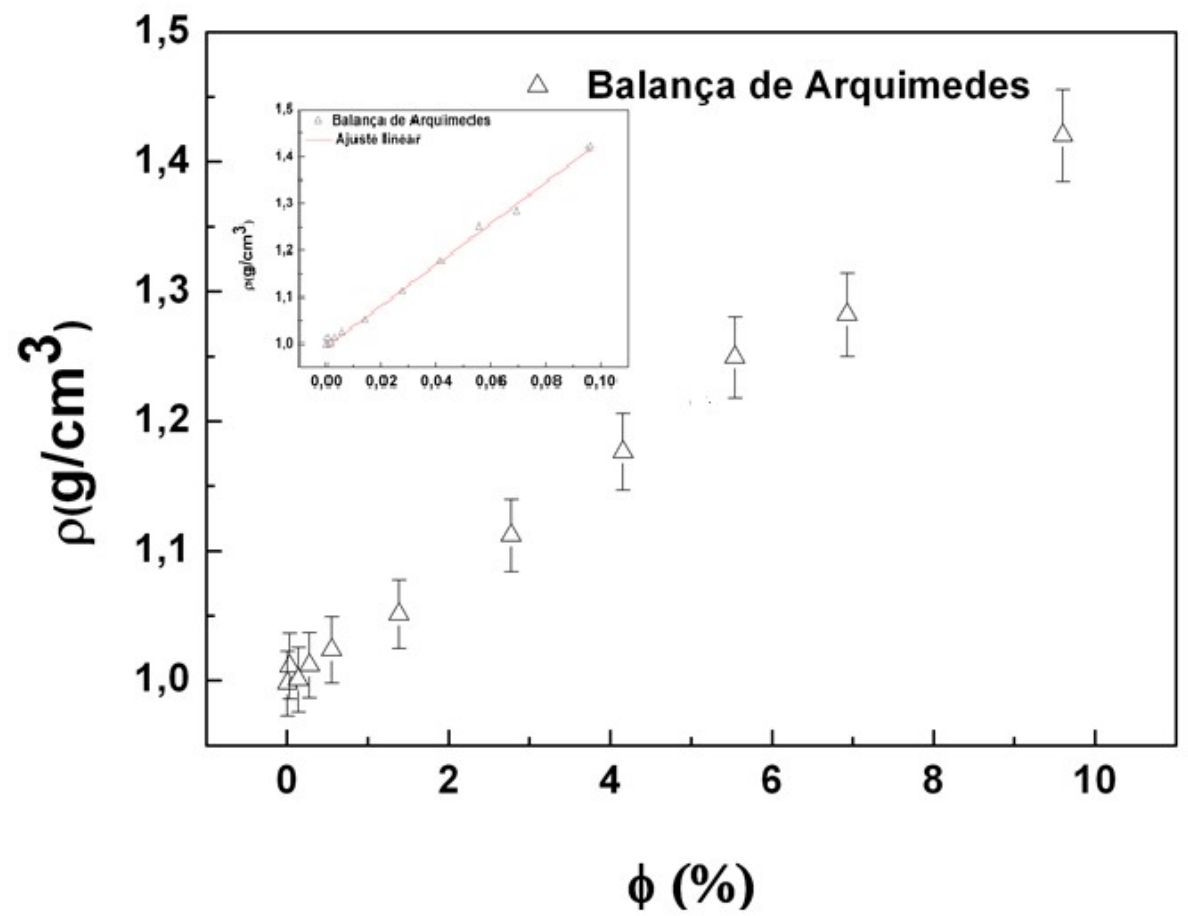

Figura 17: Densidade em função da fração volumétrica $\left(\phi_{p}\right)$ medidas na balança de Arquimedes. O detalhe mostra o ajuste dos dados experimentais com a expressão $\rho_{F F}=\rho_{S} \phi_{p}+\rho_{H_{2} O}\left(1-\phi_{p}\right)$.

Apresentamos no detalhe da figura 17 o ajuste dos dados experimentais com a expressão 22, onde foi possível obter a densidade das nanopartículas que compõe o líquido magnético, igual á $5,38 \mathrm{~g} / \mathrm{cm}^{3}$. Este valor é comparado na tabela abaixo, com o 
valor obtido através das medidas usando o densímetro DM38 e com os valores calculados a partir da equação 12 e da ponderação de cada fase pela sua fração volumétrica, da seguinte maneira $\rho_{S}=\left(\frac{\phi_{S}}{\phi_{P}}\right) \rho_{\text {Shell }}+\left(\frac{\phi_{S}}{\phi_{P}}\right) \rho_{\text {Core }}$.

Tabela 5: $\rho_{S}$ (Arquimedes) - é a densidade obtida a partir do ajuste da equação 22 utilizando a balança de Arquimedes, $\rho_{S}$ (DM38): é a densidade obtida a partir do ajuste da equação 22, utilizando o densímetro DM38, , $\rho_{\text {Calc }}:$ densidade calculada a partir da equação $12, \rho_{\text {Calc1 }}:$ densidade calculada a partir da equação $\rho_{S}=\left(\frac{\phi_{S}}{\phi_{P}}\right) \rho_{\text {Shell }}+\left(\frac{\phi_{S}}{\phi_{P}}\right) \rho_{\text {Core }}$.

\begin{tabular}{|c|c|c|c|}
\hline$\rho_{S}$ & $\rho_{S}$ & $\rho_{\text {Calc }}$ & $\rho_{\text {Calc1 }}$ \\
(Arquimedes) & (DM38) & 5,33 & 5,21 \\
\hline 5,38 & 5,22 & $\mathrm{~g} / \mathrm{cm}^{3}$ & $\mathrm{~g} / \mathrm{cm}^{3}$ \\
\hline
\end{tabular}

A diferença entre os valores encontrados para a densidade da nanopartícula, usando os métodos de determinação da densidade, está, provavelmente, associada ao erro intrínseco da balança de Arquimedes, que depende, sobremaneira, do rigor e habilidade do experimentalista. Entretanto, como pode ser verificado na figura abaixo, a comparação entre as curvas produz uma curva mestre comum (ver detalhe da figura 18), que quando ajustada com a equação 22 leva a um valor de densidade para a nanopartícula de $5,34 \mathrm{~g} / \mathrm{cm}^{3}$, em bom acordo com o valor teórico, o que pode ser o resultado de um aumento na estatística de dados. 


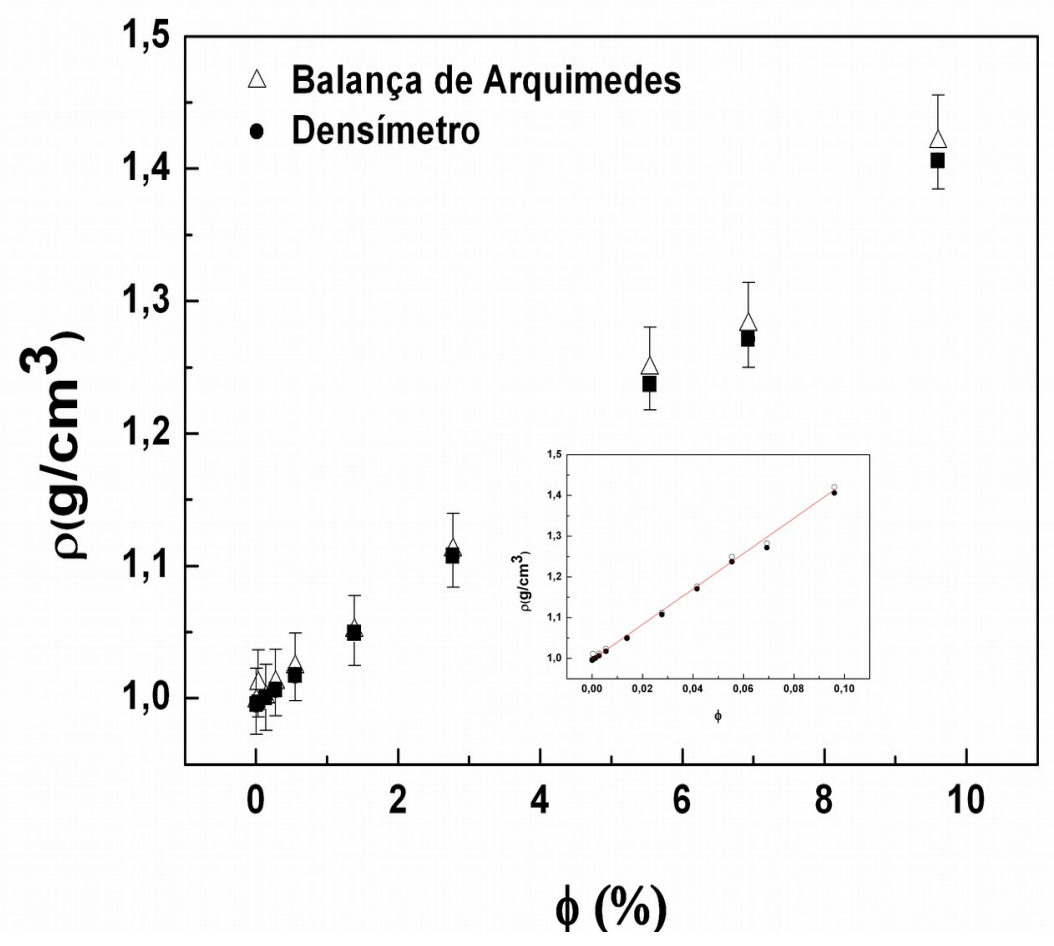

Figura 18: Comparação das densidades em função da fração volumétrica ( $\phi_{p}$ ) obtidas no densímetro e na balança de Arquimedes. $O$ detalhe mostra o ajuste dos dados experimentais com a expressão $\rho_{F F}=\rho_{S} \phi_{p}+\rho_{H_{2} O}\left(1-\phi_{p}\right)$.

\section{CONCLUSÃO}

Foram sintetizados fluidos magnéticos estabilizados em meio aquoso ácido, as nanopartículas são do tipo núcleo/superfície, com um núcleo composto por uma ferrita de cobalto $\left(\mathrm{CoFe}_{2} \mathrm{O}_{4}\right)$, recoberto por uma camada de maghemita $\left(\gamma-\mathrm{Fe}_{2} \mathrm{O}_{3}\right)$. A caracterização estrutural destes materiais foi feita utilizando a técnica de difração de raios x que apresentou um diâmetro médio de $13,94 \mathrm{~nm}$.

As nanopartículas possuem formato aproximadamente esférico o que foi observado utilizando a técnica de microscopia eletrônica de transmissão (MET). No que tange aos resultados das medidas de densidade utilizando os dois equipamentos, o densímetro do tipo DM38 e a balança de Arquimedes, os nossos resultados permitem ratificar a balança de Arquimedes como metodologia para determinação de densidade de materiais coloidais.

Contudo, o erro associado deve ser levado em conta, e devido ao fato desse erro ser muito maior que o erro associado ao densímetro digital, esta medida deve ser 
preferencial apenas nos casos de coloides muito viscosos. Ainda, algumas atitudes e práticas do experimentalista podem diminuir os erros sistemáticos associados à balança de Arquimedes, garantindo uma tomada de volume de maior acurácia para os casos de coloides concentrados.

Essas práticas podem ser divididas em duas, quais sejam: a) realizar as medidas, no mínimo, em triplicata e sempre realizar o teste Q para decidir se um dado suspeito pode ser conservado ou descartado e; b) maximizar, dentro do limite possível de preparação de amostras concentradas, a massa de cada alíquota medida na balança de Arquimedes.

Por fim, como perspectiva futura para este trabalho, medidas de densidade para coloides concentrados, tipicamente com frações volumétricas acima de 10\%, devem ser realizadas visando determinar a região a partir da qual estes materiais não fluem mais como líquidos e, portanto, devem ter alíquotas tomadas a partir de medidas de massa.

Nesse contexto, o conhecimento da densidade do coloide, com o maior grau de precisão e exatidão possível, dependerá da correta calibração da metodologia de medida usando a balança de Arquimedes. Ainda, outros fatores como o pH, a força iônica, a temperatura e a própria concentração em nanopartículas (que está relacionada com as interações interpartículas) podem influenciar nas propriedades coligativas dos sistemas coloidais e, portanto, devem ser estudadas no caso da determinação da densidade dos fluidos magnéticos. 


\section{REFERÊNCIAS BIBLIOGRÁFICAS}

[1] CHARLES, S. W.; POPPLEWELL, J.; WOHFATH, E. P. Ferromagnetic material. Vol. II. North-Holland Publishing Company: Amsterdan, 1982.

[2] ROSENSWEING, R. E; KAISER, R. Report nasa. NASA, CR-1407, 1969.

[3] PAPELL, S. Low viscosity magnetic fluid obtained by the coloidal suspension of magnetic particle. Filed Oct. 9, 1963.

[4] BARAlE, M; LEFÈVRE, G.; CARRETTE, F.; CATALETTE, H.; FÉDOROFF, M.; COTE, G. Effect of the adsorption of lithium and borate species on the zeta of particles of cobalto ferrite, nichel ferite, and magnetite. Jounal Colloid and Interface Science, 328, 34-40, 2008.

[5] PANKhurst, Q. A.; CONNOLly, J.; JONES, S. K.; DOBSON, J. Applications of magnetic nanoparticles in biomedicine. Journal of Physics D: Applied Physics, v. 36, n. 13, p. R167, 2003.2

[6] PANKHURST, Q. A.; THANH, N. T. K.; JONES, S. K.; DOBSON, J.Progress in applications of magnetic nanoparticles in biomedicine. Journal of Physics D: Applied Physics, v. 42 , n. 22 , p. 224001,2009 .

[7] ROSENSWEING, R. E. Ferrohydrodynamics. Cambrigde University: Cambrigde, 1985.

[8] MASSART, R.; IEEE Trans on Magn. 17, 1247, 1981.

[9] GOMES, J. A.; SOUSA, M. H.; TOURINHO, F. A; AQUINO, R.; SILVA, G. J.; DEPEYROT, J.; DUBOIS, E. and PERZYNSKI, R. Syntesis of Core Shell Ferrite

Nanoparticles for Ferrofluids: Chemical and Magnetic Analysis. The Journal of Physical Chemistry C, 112(16):6220-6227, 2008.

[10] KITTEL, C. Introduction to Solid State Physic. Hoboken/NJ: Wiley, 1976.

[11] GUINER, A. The basics of crystallography and difraction. Freeman, San Francisco: Third Edition, 2009.

[12] HAMMOND, C. X-Ray Diffraction, Imperfect Crystals and Amorphous Bodies. New York, USA: Oxford University Press, 1994.

[13] WEST, D. M.; CROUCH, S. R.; SKOOG, D. A.; HOLLER, F. J. Fundamentos de Química Analítica. São Paulo: Thomson Pioneira, 2015. 
[14] SCHERER, C. and FIGUEIREDO NETO, A. M.. Ferrofluids: properties and applications. Braz. J. Phys. [online]. 2005, vol. 35, n. 3a, p 720. Disponível em: http://dx.doi.org/10.1590/S0103-97332005000400018.

[15] PASHLEY, M. R.; KARAMAN, E. M. Applied Colloid and Surface Chemistry. Canberra: John Wiley e Sons Ltda., 2004, p. 99.

[16] SILVA, O. Síntese e caracterização de fluidos magnéticos de ferrita de cádmio. 2006. 159 f. Tese (Doutorado em Física) - Universidade de Brasília, Brasília, 2006, p. 43.

[17] POPIOSLKI, T. M. Avaliação da Incorporação de Nanopartículas de ouro em Filmes Automontados de Polieletrólitos Fracos. 88 f. Dissertação (Mestrado em Materiais) - Universidade de Caxias do Sul, Caxias do Sul, 2011, p. 36.

[18] ISRAELACHVILI, J. Intermolecular and Surface Forces. 2. ed. London: Elsevier Academic Press, 1991; BLOSS, D. A. Crystallography and Crustal Chemistry: an Introduction. New York: Rinderhart and Winston Inc, 1994.

[19] GOLDMAN, A. Modern Ferrite Technology. Springer, 2010.

[20] KLUG, H. P; ALEXANDER, L. E. X ray di_raction procedures. Canberra: John Wiley e Sons Ltda., 1981.

[21] W.; C. S. Popplewell. Ferromagnetic liquids in ferromagnetic materials. In: Vol. 2. E. P. Wohlfarth (Ed.). 1980.

[22] ALVES, C.; AQUINO, R.; DEPEYROT, J.; TOURINHO, F.; DUBOIS, E.; PERZINSKI, R. Superparamagnetic relaxation evidences large surface contribution for the magnetic anisotropy of $\mathrm{MnFe}_{2} \mathrm{O}_{4}$ nanoparticles of ferrouids. In: Journal of Materials Science, v. 42, n. 7, p. 2297, 2303; 2007.

[23] RODRIGUES, P. C. de S. Elaboração e Caracterização de Nanocoloides Magnéticos em Elevadas Frações Magnéticas. 2010. 104 f. Dissertação (Mestrado em Química) - Universidade de Brasília, Brasília, 2010, p. 44.

[24] SCHERER, G.; DUBOIS, E.; DUPUIS, V.; PERZYNK, R.. In: J. Phys: Condens. Matter. n. 18, 2006, p. 10119.

[25] TRONC, E. and BONNIN, D. Magnetic coupling among spinel iron oxide microparticles by mössbauer spectroscopy. In: J. Physique Lett, 46(10), pp. 437-443, 1985.

[26] HIEMENZ, P. C.; RAJAGOPALAN, R. Principles of Coloidal and Surface Chemistry. 3rd ed. New York: Marcel Dekker Inc., 1997. 
[27] SILVA, F. G. da. Propriedades de exchange bias e congelamento de spins de superficie em nanopartículas magnéticas. 2009. 77 f. Dissertação (Mestrado em Física)-Universidade de Brasília, Brasília, 2009, p. 15.

[28] VIALI, W. R. Synthesis and characterization of oleic acid coated maghemite nanoparticles to obtain insulating oil based magnetic fluids. 2009. 100 f. Dissertação (Mestrado em Educação em Química) - Universidade Federal de Goiás, Goiânia, 2009, p. 38 .

[29] HUNTER, J. Fundations of Colloid Science. Oxford: Clarendo Press, 2000.

[30] BLUCHER, E.; SHAW, D. J. Introdução a Química dos Colóides e de Superfícies. São Paulo: Editora da USP, 1975.

[31] MARINHO, E. P. Síntese, caracterização físico-química e eletroquímica de dispersões coloidais magnéticas do tipo EDL (Eletric Double Layered) a base de ferritas espinélio. 2011. ix, 133 f., il. Tese (Doutorado em Química) - Universidade de Brasília, Brasília, 2011.

[32] CUllity, B. D. Introduction to Magnetic Materials. Philippines: Addison Wesley Publishing Company, 2010. 